\title{
The Shrinkage After the Enlargement? The Effect of Financial Crises and Enlargement on Stock Market Integration in the Euro Area
}

\author{
Maela Giofré ${ }^{1} \&$ Oleksandra Sokolenko ${ }^{2}$ \\ ${ }^{1}$ University of Turin, Italy \\ ${ }^{2}$ University of Roma Tre, Italy \\ Correspondence: Maela Giofré, Department of Economics and Statistics "Cognetti de Martiis", University of \\ Turin, Lungo Dora Siena 100, 10153 Torino, Italy. Tel: 390-116-704-980.
}

Received: January 7, 2021

Accepted: January 26, 2022

Online Published: February 10, 2022

doi:10.5539/ijef.v14n3p33

URL: https://doi.org/10.5539/ijef.v14n3p33

\begin{abstract}
The bilateral foreign portfolio equities among Euro area members have shrunk by 40 percent after 2007. While both the financial crisis and the enlargement are potentially responsible of this abrupt and persistent contraction in financial integration, our work detects a major role for the crisis. The deterioration of the control of corruption mechanisms in Euro periphery economies occurred during the crisis is identified as a plausible driver of this shrinkage.
\end{abstract}

Keywords: stock market integration; common currency; financial crisis; EMU enlargement

JEL classification: F21, F30, F36, G11, G15.

\section{Introduction}

Since the inception of the European Economic and Monetary Union (EMU), a great deal of research has been devoted to investigating its impact on the degree of financial integration.

By analyzing the Eurozone financial integration, the literature unequivocally maintained the tendency of the Eurozone countries to disproportionately invest in their partners compared to other countries, both for bilateral bond holdings (Lane, 2006; Giofré, 2013), and for bilateral equity holdings (Lane \& Milesi-Ferretti, 2007; Balta \& Delgado, 2009; Berkel, 2004; Slavov, 2009; Sousa \& Lochard, 2011). Allen and Song (2005) confirm a similar evidence for cross-border direct investments and cross-border merger and acquisition activities.

Over more than 20 years, the EMU has been challenged by wide-ranging events, which potentially could have jeopardized the integration process. Two are the major suspects, deflagrating almost contemporaneously: the EMU enlargement process and the global financial crisis.

There is a lively debate on the consequences of global events, such as financial crises, on the process of financial integration. Hartmann et al. (2004) and Brière et al. (2012), consider the changes in financial markets due to the effects of globalization. Longstaff (2010) shows in his study the contagion effect of subprime CDOs on other financial markets, and Vermeulen (2013) proves a negative relationship between foreign equity holdings and stock market correlations during the financial crisis. Broner et al. (2013) and Lane (2013) confirm a general decrease in total investments and a collapse in capital flows in crisis periods. Milesi-Ferretti and Tille (2011) specify that the financial crisis hit mostly the advanced economies featuring a higher level of financial integration, and less the emerging economies.

On the other hand, the extant literature suggests that the inclusion of new members in the monetary union might have significantly tilted the existing equilibria in the area. Lane (2008) shows that the EMU effect is greater for those countries characterized by a less-developed financial system. Giofré (2012) demonstrates how the single currency seems to have promoted a quicker financial convergence among EMU members, as countries very distant before the adoption of the euro have been the fastest to converge. More specifically related to the enlargement process, Baltzer et al. (2008) point out that the new members had a much lower level of integration, but, since their entry in the EU, they have also started a reverse trend. Dunis et al. (2013) show that the integration process seems to be different for each country, more visible from the entry in the EU, and less clear after the adoption of the euro. Masten et al. (2008) expect the financial integration of those new members to 
become faster after the adoption of the single currency. Recently, Harckmann (2020) find that there is no stock market integration between the euro area and the Baltic republics, the latter can provide diversification benefits for the euro area indices. Lane and Milesi-Ferretti (2017) confirm, relatively to fixed securities markets, that the new members of the Euro area have increased their level of integration with the others EMU members.

Within the evidence of a general downfall of international financial flows documented by the literature (Lane, 2013; Milesi-Ferretti \& Tille, 2011), this paper brings to light that after 2007 bilateral cross-border portfolio equity holdings within the EMU area fell more abruptly and persistently than for other country-pairs.

Due to their contemporaneous occurrence, any of the two explanations, financial crisis or enlargement, or any combination of the two, can be recognized as responsible of the abrupt and persistent decline in stock market integration among EMU member countries. Indeed, both the financial crisis and the enlargement process are consistent with long lasting effects: on the one hand, the financial crisis persisted in the European landscape turning into the sovereign debt crisis, and, on the other hand, the enlargement process has lasted for several years, with the progressive staggered entry of new members.

To assess the role of these two main events, we scrutinize the dynamics of different groups, the original EMU members and the new ones.

Our findings highlight that the crisis has drastically weakened the linkages among original members: a peculiar decline in economic development and, more importantly, a deterioration of the control of corruption standards in Euro periphery countries, those more severely injured in the sovereign debt crisis, induced a sharp decrease of their inward investments by the Euro area as a whole.

Furthermore, the inclusion of new countries, with lower economic development and weaker institutional standards than the original members, has not helped the cohesion within the enlarged EMU area: while new members have mildly increased their portfolio holdings in the old EMU countries, their equities have been exerting a low financial attractiveness upon old members.

The remainder of the paper is structured as follows. In Section 2, we sketch the estimable equation. In Section 3, we describe the data and discuss some descriptive statistics. In Section 4, we perform the empirical analysis and discuss the main results. In Section 5, we provide a tentative assessment of the relative role of the crisis and the enlargement process in shaping the evolution of the EMU's bilateral foreign portfolio equities. In Section 6, we try to interpret the evidence, in the light of the role of size and institutions. Section 7 analyzes the investment patterns of Euro core and periphery countries. Section 8 summarizes and concludes.

\section{Estimable Equation}

Our baseline estimation builds on the following specification (Note 1):

$$
\begin{aligned}
\log \left(F P E_{s h}\right)= & \alpha+\sum_{j=1, \ldots, J} \beta^{j} X_{h}^{j}+\sum_{k=1, \ldots, K} \varphi^{k} Y_{s}^{k}+\sum_{l=1, ., L} \delta^{l} Z_{s h}^{l}+ \\
& \sum_{m=1, ., M} \theta^{m} \log \left(Q_{h}^{m}\right)+\sum_{n=1, ., N} \rho^{n} \log \left(T_{s}^{n}\right)+\sum_{p=1, \ldots, P} \sigma^{p} \log \left(W_{s h}^{p}\right)+\gamma D+\varepsilon_{s h}
\end{aligned}
$$

The dependent variable $\log \left(F P E_{s h}\right)$, is the logarithm of the foreign portfolio equities (FPE) of source country $s$ in host country $h$.

Our regression specification accounts for pair-specific regressors $\left(Z_{s h}\right.$ or $\left.W_{s h}\right)$, such as gravity variables, country-specific variables $\left(X_{h}, Y_{s}, Q_{h}, T_{s}\right)$, such as size and institutional variables, and time factors $(D)$.

Among these covariates, continuous regressors $\left(Q_{h}, T_{s}\right.$ and $\left.W_{s h}\right)$ are expressed in logarithmic terms, so that their coefficients, being the dependent variable also defined in logs, can be easily interpreted in elasticity terms (e.g., if a significant coefficient is equal to 0.3 , then a $10 \%$ increase in the regressor induces a $3 \%$ increase in the dependent variable). Conversely, the effect of a dichotomous variable $\left(X_{h}, Y_{s}\right.$ and $\left.Z_{s h}\right)$ on a dependent variable expressed in $\operatorname{logs}$ is captured by the following transformation of its coefficients $\beta$ : $\mathrm{e}^{\beta}-1$ (e.g., if a significant coefficient $\beta$ is equal to 0.3 , then the effect of a dummy equal to 1 on the dependent variable is $\mathrm{e}^{0.3}-1=0.35$, to be interpreted as the effect being 35\% larger than the effect of a dummy equal to 0 ) (Note 2).

Among these variables, the dummies capturing the EMU country membership are crucial for our analysis. $E M U_{s h}$ is a bilateral-specific dummy variable taking value 1 when both the source country $s$ and the host country $h$ are EMU members, 0 otherwise; $E M U_{s}$ (or $E M U_{h}$ ) is instead a country-specific dummy variable equal to 1 when the source country (or host country) is a EMU member, 0 otherwise.

Finally, $D$ is a dummy capturing the time dimension in terms of years or, more meaningful for our purposes, in 
terms of occurrence of peculiar events, such as periods of crisis, which allows us to detect any global shift in foreign investment due to macroeconomic shocks.

The econometric specification (1) is enriched throughout the analysis to include interactions with the EMU dummies, to seize the eventual incremental or erosive role played by other factors (A), such as the crisis, on the EMU linkages (Note 3).

$$
\log \left(F P E_{s h}\right)=\alpha+\beta E M U_{*}+\gamma A+\delta E M U_{*} \cdot A+\text { controls }+\varepsilon_{s h}
$$

Through a Difference-in-Difference approach, we aim at seizing how a factor $A$, e.g., the crisis variable, affects FPE among EMU countries, on top of the global effect played by $A$ on FPE.

The econometric strategy adopted follows Santos Silva and Tenreyro (2006) who explicitly address, within the standard trade log gravity models, the problem of inflation of zero investment data and the need to get estimates robust to different patterns of heteroskedasticity (Note 4). Accordingly, we model the dependent variable $F P E_{s h}$ as following a Poisson distribution, applying the Poisson Pseudo-Maximum Likelihood estimator with individual fixed effect - that in our case corresponds to country-pair fixed effects - and standard errors clustered by year.

\section{Data and Descriptive Statistics}

\subsection{Data}

We consider the bilateral equity portfolio investments of 68 countries, for the period 2001-2017 (Note 5). We adopt the Coordinated Portfolio Investment Survey (CPIS), released by the IMF, a dataset which has been used in many recent papers (Fidora et al., 2007; Lane \& Milesi-Ferretti, 2007; Sorensen et al., 2007; Giannetti \& Koskinen, 2010; Giofré, 2013). This survey collects security-level data from the major custodians and large end-investors. Portfolio investment is broken down by instrument (equity or debt) and residence of issuer, the latter providing information on the destination of portfolio investment. While the CPIS provides the most comprehensive survey of international portfolio investment holdings, it is still subject to a number of important caveats (Note 6). The most important is that the CPIS is unable to address the issue of third-country holdings and round-tripping, very frequent in the case of financial offshore centers. Following the more recent literature on offshore center classifications, we exclude from our sample "the eight major pass-through economies - the Netherlands, Luxembourg, Hong Kong SAR, the British Virgin Islands, Bermuda, the Cayman Islands, Ireland, and Singapore-[hosting] more than 85 percent of the world's investment in special purpose entities, which are often set up for tax reasons" (Damgaard et al., 2018) (Note 7).

Details on the definition of the dependent variable and regressors, and information on their respective sources, are reported in Appendix A.

\subsection{Descriptive statistics}

Table 1 reports the variables included in our analysis and their main descriptive statistics. The subscript $s h$ refers to bilateral covariates, while " $*$ " indicates that the corresponding country-specific variable enters the analysis for both the destination and the investing country.

The first panel reports data on the dependent variable, i.e., the bilateral portfolio equities holdings expressed in US\$. They range from zero to 1295 billions of US\$, with a median of 8.10 millions and a standard deviation of 29 billions (Note 8).

The second panel groups the size variables, such as GDP per capita, GDP in US\$, and stock market capitalization. The analysis of GDP per capita of source and host countries points out a large dispersion among countries. On average, the GDP per capita is 24327 US\$, while $50 \%$ of the sample has a GDP per capita lower than 16681 US\$. The minimum value is equal to 447 US\$, while the maximum is 119225 US\$, with a standard deviation of 21977 US\$. A notable degree dispersion is also present for the GDP in US\$ and for stock market capitalization.

In the third panel, we group all the bilateral gravity variables. With the only exception of the distance variable, these are dummy variables: they capture if country pairs share a border, colonial linkages, a common language, or legal origins.

The fourth panel shows the values of the capital mobility variable, with a rank ranging from 0 to 10 to indicate increasing levels of capital mobility, and with an average equal to 4.48 . The first quartile of the countries is equal to 1.54 , while the third quartile reports a ranking equal to 6.92 .

Finally, the last panel reports the institutional variables, such as "control of corruption", "rule of law", 
"government effectiveness" and "regulatory quality" drawn from the Worldwide Governance Indicators (WGI, World Bank), and the "perceived control of corruption" (Transparency International) (Note 9). These variables' rank goes from zero to 100 , reflecting an increasing country governance index. For instance, the mean rank for the "control of corruption" index is around 68.74, only $25 \%$ of countries report a result lower than 51.38, while another $25 \%$ of countries are ranked over 91.20 , with a standard deviation equal to 25.40 .

Table 1. Descriptive statistics

\begin{tabular}{|c|c|c|c|c|c|c|c|}
\hline \multirow[b]{3}{*}{ I. Dependent variable } & \multicolumn{7}{|c|}{ Descriptive Statistics } \\
\hline & Min & 1st Qu & Median & Mean & $3 \mathrm{rd} \mathrm{Qu}$ & Max & St. dev \\
\hline & & & & & & & \\
\hline & 0 & 0 & $8.10 \mathrm{E}+06$ & 4.18E+09 & $3.04 \mathrm{E}+08$ & $1.29 \mathrm{E}+12$ & $2.901 \mathrm{E}+10$ \\
\hline \multicolumn{8}{|l|}{ II. Size variables } \\
\hline Market cap* ${ }_{*}$ US \$) & $3.80 \mathrm{E}+07$ & $3.70 \mathrm{E}+09$ & $3.55 \mathrm{E}+10$ & $4.30 \mathrm{E}+11$ & $1.75 \mathrm{E}+11$ & $1.47 \mathrm{E}+13$ & $1.80 \mathrm{E}+12$ \\
\hline GDP per cap* $($ US \$) & 447.00 & 7262.00 & 16681.00 & 24327.00 & 38166.00 & $1.19 \mathrm{E}+05$ & 21976.61 \\
\hline $\mathrm{GDP}_{*}(\mathrm{US} \$)$ & $1.27 \mathrm{E}+09$ & $4.80 \mathrm{E}+10$ & $2.14 \mathrm{E}+11$ & $8.02 \mathrm{E}+11$ & $5.54 \mathrm{E}+11$ & $1.94 \mathrm{E}+13$ & $2.07 \mathrm{E}+12$ \\
\hline GDP $*$ world ratio & 0.0000 & 0.0006 & 0.0034 & 0.0128 & 0.0087 & 0.3180 & 0.0336 \\
\hline \multicolumn{8}{|l|}{ III. Gravity variables } \\
\hline Distance $_{\mathrm{s}, \mathrm{h}}$ (miles) & 59.62 & 2781.71 & 7364.45 & 7207.36 & 10159.53 & 19772.34 & 4735.46 \\
\hline Border dummy $y_{s, h}$ & 0 & 0 & 0 & 0.03 & 0 & 1 & 0.17 \\
\hline Colonial dummy $y_{\mathrm{s}, \mathrm{h}}$ & 0 & 0 & 0 & 0.05 & 0 & 1 & 0.22 \\
\hline Language dummy $_{\mathrm{s}, \mathrm{h}}$ & 0 & 0 & 0 & 0.11 & 0 & 1 & 0.31 \\
\hline Legal origins dummy $\mathrm{s}_{\mathrm{s}, \mathrm{h}}$ & 0 & 0 & 0 & 0.25 & 0 & 1 & 0.43 \\
\hline \multicolumn{8}{|l|}{ IV. Capital mobility } \\
\hline Capital mobility* & 0.00 & 1.54 & 4.62 & 4.48 & 6.92 & 10.00 & 2.82 \\
\hline \multicolumn{8}{|l|}{$\underline{V . \text { Institutional variables }}$} \\
\hline Rule of Law* & 0.50 & 53.80 & 76.55 & 70.13 & 90.60 & 100.00 & 24.07 \\
\hline Gov Effectiveness* & 7.70 & 58.95 & 78.40 & 73.32 & 90.72 & 100.00 & 20.65 \\
\hline Regulatory quality* & 2.40 & 59.80 & 78.50 & 73.14 & 91.12 & 100.00 & 21.51 \\
\hline Control of Corruption $*$ & 4.30 & 51.38 & 72.45 & 68.74 & 91.20 & 100.00 & 25.40 \\
\hline Perceived Control of Corruption & 17.00 & 37.00 & 53.00 & 56.33 & 75.00 & 99.00 & 21.86 \\
\hline
\end{tabular}

Note. This table reports the descriptive statistics of the dependent variable and the regressors used in the analysis. The subscript $s h$ refers to the country-pair $s h, *$ indicates that the corresponding variable is included in the analysis for both the destination and the investing country.

\section{Empirical Analysis}

\subsection{Preliminary evidence}

In Figure 1, we report the dynamics of FPE. Panel a) displays the staggered entry of new members in the EMU, and the pre-crisis, crisis, and post-crisis time spans. Bilateral portfolio equities (FPE) are regressed on the bilateral $E M U_{s h}$ dummy, year dummies $D$, and their interaction $E M U_{s h} \cdot D$, to seize the change in the impact of the $E M U_{s h}$ dummy on FPE over time:

$$
\log \left(F P E_{s h}\right)=\alpha+\beta E M U_{s h}+\gamma D+\delta E M U_{s h} \cdot D+\varepsilon_{s h}
$$

Normalizing to 1 the effect of the common currency in 2001, Figure 1 displays the trend of the EMU effect on bilateral portfolio foreign investments. The changes over time in foreign portfolio equity investment (FPE) from the original 2001 value are significantly different from zero. We can observe, first, that over the whole period we can record a positive role of the common currency on cross-border portfolio investment; second, there has been a decreasing EMU effect from 2007 onward with no recovery, but rather a slow decline down to 40 percent of its initial level.

However, the occurrence of global shocks might have shifted cross-border foreign investments for all countries, regardless of their EMU membership. Panel b) of Figure 1 reports the trend of bilateral foreign investment over years for all countries in the sample, estimated as follows:

$$
\log \left(F P E_{s h}\right)=\alpha+\beta D+\varepsilon_{s h}
$$




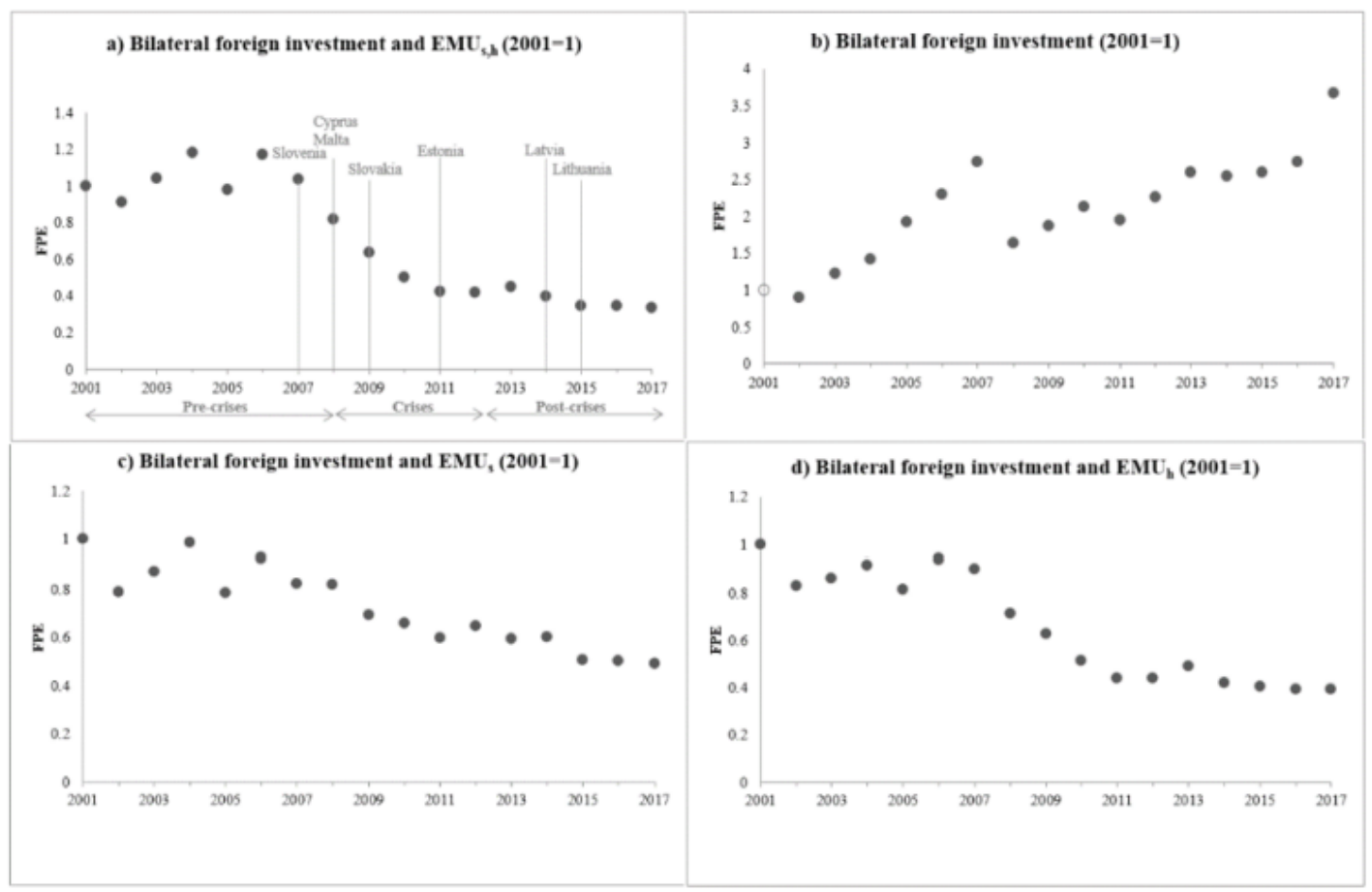

Figure 1. Bilateral Foreign Portfolio Equity investment (FPE)

Note. This figure reports the dynamics of the bilateral FPE over time. Panel a) reports the regression coefficients of FPE with the bilateral dummy $E M U_{s h}$ interacted with year dummy (equation (3), in the main text, where $E M U_{*}=E M U_{s h}$ ). The figure also displays the entry of new EMU members and the period split adopted in the paper (Pre-crisis, Crises, and Post-crises). Panel b) reports the regression coefficients of FPE on year dummy (equation (4)), in the main text). Panel c) and d) report the regression coefficients of FPE on the bilateral dummy $E M U_{s}$ (or $E M U_{h}$ ) interacted with year dummy (equation (3), in the main text, where $E M U_{*}=E M U_{s}$ or $E M U_{h}$ ). The value of the coefficient in 2001 is normalized to 1 and the other coefficients are obtained relative to the 2001 value.

After normalizing to one its average value in 2001, the figure displays an increasing pattern of FPE in the world until 2007, a drop in 2008 and then a recovery up to a level more than 3 times larger than its initial level. The drop in this graph reflects the abrupt fall in financial flows due to the financial crisis recorded by the literature (Lane, 2013; Milesi-Ferretti \& Tille, 2011).

By comparing panel a) and b) of Figure 1, we notice that, similarly to the global trend, also EMU countries show a significant drop in reciprocal cross-border investment, but differently from the global trend, this pattern has not reversed after the crisis. This suggests that Euro area specific dynamics can be responsible of the persistence in the decline of FPE among member countries.

In panel c) and d) of Figure 1, we scrutinize the role played by EMU member countries, respectively, as investing $\left(E M U_{s}\right)$ or as recipient economies $\left(E M U_{h}\right)$. The two graphs contribute to show the relatively poor performance of EMU countries relative to the world, since 2007 onwards, both as investing and as recipient economies: we observe a sharp decline with the crisis, and then a slow persistent decrease. On average, EMU countries have become less performing as investing economies, and even less attractive as host economies.

To understand what has driven these results, we need to seize, in a multivariate regression, the role of the two main events that involved the EMU countries: the financial crisis, followed by the sovereign debt crisis in the Euro area (crisis effect), and the enlargement process (enlargement effect).

\subsection{Main Findings}

\subsubsection{The Dynamics of EMU Linkages}

Table 2 shows the effect of the bilateral EMU dummy, $E M U_{s h}$, on bilateral foreign portfolio equity holdings. The dependent variable is the log of bilateral foreign equity investment (FPE). Regressors are reported at the head of the rows. As specified above, the coefficients of all regressors expressed in logs can be interpreted in elasticity terms, while the effect of dummy variables on the dependent variable is captured by the coefficient $\beta$ as follows: $e^{\beta}-1$. 
Table 2. FPE and EMU

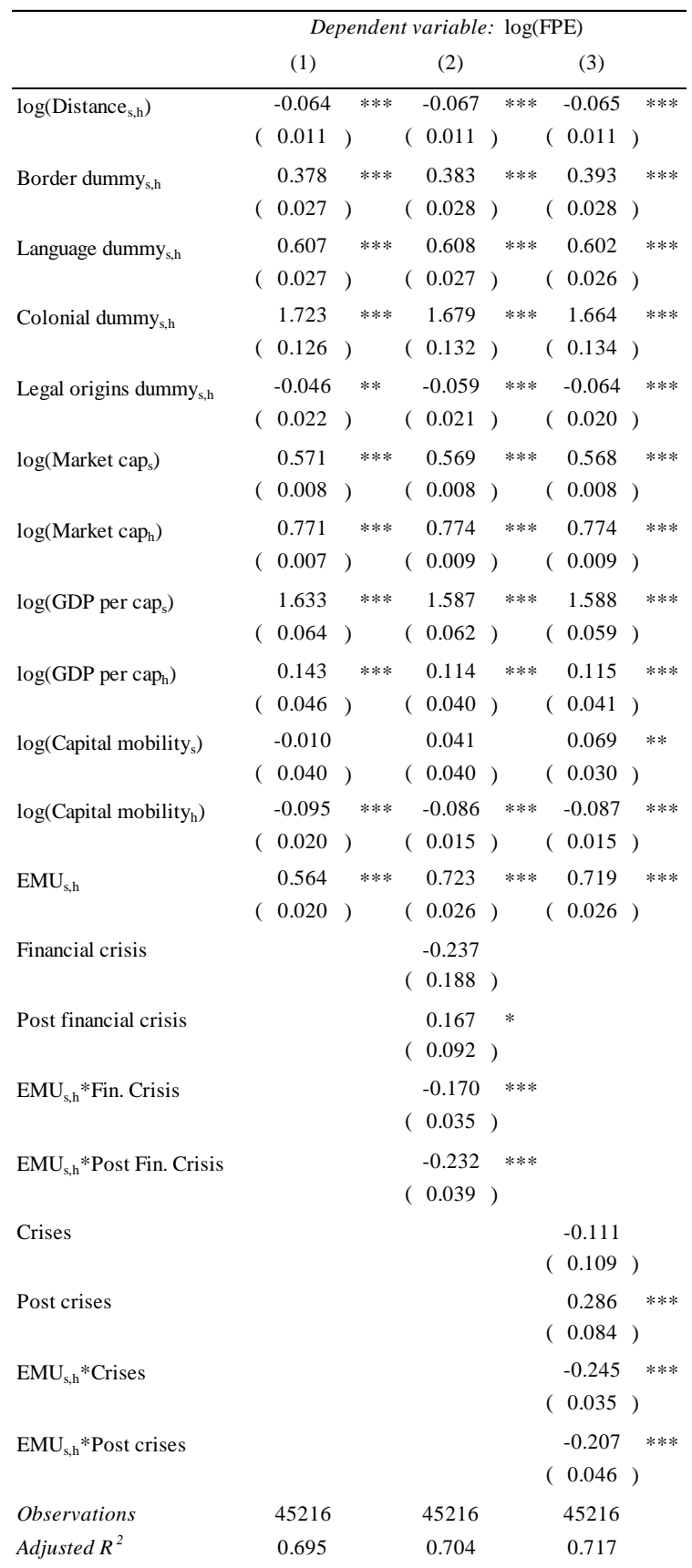

Note. This table reports the results of a Poisson Pseudo Maximum Likelihood regression (Santos Silva and Tenreyro (2006)), as from equation (2) in the main text, with individual country pair fixed-effects and robust standard errors clustered by year. The dependent variable is $\log \left(F P E_{s h}\right)$, where the subscript $s h$ represents the couple investing country $s$-destination country $h . * * *, * *$, and $*$ indicate significance at the 1,5 , and $10 \%$ levels, respectively.

In column 1, we consider the standard gravity variables used in literature to define the cultural and geographic proximity between two countries, both for equity flows (Portes \& Rey, 2005; Portes et al., 2001), and for equity holdings (Chan et al., 2005). These variables include the distance between the capital cities of country $s$ and country $h$, the border dummy (equal to 1 for each country pair sharing a common border, 0 otherwise), the language dummy (equal to 1 when the country $s$ and the country $h$ share the same language, 0 otherwise), the colonial dummy (equal to 1 for those pairs of countries sharing a common colonial past, 0 otherwise), and the legal origin dummy variable (equal to 1 when investor and destination countries have a common legal origin, 0 otherwise). We expect geographical and cultural proximity to have a positive impact on foreign portfolio equities, 
as a decrease in physical and cultural distance reduces information costs, and then enhances investment by foreign investors.

Consistently with the gravity model approach, we also include the size variables, which express the economic weight of the investing and host countries, such as market capitalization and GDP per capita, and, finally, we control for capital mobility.

The results confirm that the gravity variables have a strong impact on the FPE allocation. The distance variable displays a negative coefficient (-0.064), meaning that an increase in distance between capital cities is associated with a decrease in foreign portfolio equities (Note 10). Sharing a common border leads to an increase of FPE by $46 \%\left(\mathrm{e}^{0.378}-1=0.46\right)$, having an official language in common increases FPE by $83 \%$, having a common colonial past increases equities share by 4.6 times, while the common legal origin seems to marginally decrease FPE by $4 \%$ $\left(\mathrm{e}^{-0.046}-1=-0.04\right)$. The contribution of the size variables also appears important. Stock market capitalization has a significant and positive impact on the FPE, which appears to be stronger for the host $(0.771)$ than for the source country (0.571). The balance is reversed for the GDP per capita variable: while an increase in the source country's GDP strongly fosters foreign investment, the effect in the host countries is much lower. Capital mobility variables play a non-significant role on the investing size, and a modest negative impact on the host side.

The coefficient of the bilateral EMU dummy variable over the whole period is equal to 0.563 , that is, EMU countries invest one another $76 \%$ more than other country-pairs.

In column (2) of Table 2, we try to capture the time variation of the EMU dummy, by identifying the financial crisis (2008-2009) and the post-financial crisis period (2010-2017). The coefficients of the crisis dummy (non-significant) and of the post-financial crisis dummy (marginally positive), capture the impact of these two periods on bilateral FPE of non-EMU country pairs. We observe that the coefficient of the $E M U_{s h}$ dummy, which refers to the excluded time span, i.e., the pre-financial crisis period, is large, positive and statistically significant: EMU members used to invest one another $106 \%$ more than non-EMU country pairs in the pre-crisis period. The effects of the EMU dummy in the subsequent periods are computed by adding the coefficients of the corresponding interaction terms to the non-interacted one.

The negative coefficient of the interaction term $E M U_{\text {sh }} \cdot$ Financial crisis can be interpreted as the change of the EMU effect (on FPE) induced by the crisis (or, symmetrically, as the change of the crisis effect on FPE for EMU country pairs). It is negative and significant, thus suggesting a significant drop (from 106\% to $74 \%$ ) in the EMU effect on FPE relative to the pre-crisis period (or, symmetrically, a more negative effect of the crisis for EMU country pairs). The negative coefficient of the interaction between the EMU dummy and the post-financial crisis period shows a further drop compared to the financial crisis period, with the EMU effect shrinking to 63\%.

After the global financial crisis, the Europe has been flawed by another violent crisis, the European sovereign debt crisis (2010-2012). In column (3) of Table 2, we consider both crises together, so that the post-crises period starts in 2013.

We observe a large drop in FPE among the source and host countries of the euro area during the crises period (financial and sovereign debt crises) from $105 \%$ to $61 \%$, with only a very marginal recovery after the crises. As far as non-EMU country pairs are considered, instead, the coefficient of the crises period is non-significant, while the positive significant coefficient for the post crises period highlights the general recovery after the crisis, outside the Eurozone.

The results in Table 2 confirm, in a multivariate setting, the preliminary evidence of Section 4.1: after 2007, the drop in the common currency effect on bilateral FPE highlights that the linkages among EMU countries have significantly loosened. The fall in the EMU effect can be due to a slackening of the linkages among the original members because of the crisis, and/or to the inclusion of new countries less connected with the euro area. To better understand the phenomenon, we need to scrutinize, within the aggregate euro area, the different dynamics of its sub-groups over time.

\subsubsection{Group Decomposition of EMU}

In Table 3, we restrict to OLD EMU countries, the original members: by keeping constant the composition of the EMU group, the within-OLD EMU investments (i.e., the foreign holdings among original EMU members) should help isolate the effect of the crisis. A comparison of the investment within-OLD EMU with the dynamics of investment between OLD-EMU and the whole EMU group (new and old), will allow us to detect, by difference, the role of the enlargement.

In fact, it is impossible to investigate the investment dynamics (pre-crisis, crisis, and post-crisis) of NEW EMU 
countries as a separate group, because their entry in the EMU group occurred since 2007 onward. We try to circumvent this problem by observing the investment patterns of OLD EMU over time, and then the investment patterns of the whole EMU group, which comprises, beyond OLD EMU countries, also NEW EMU after 2007, as far as they started entering the common currency area. By comparing these two patterns, we try indirectly to infer the role played by the enlargement, on top of the crisis.

In Table 3, we decompose the EMU foreign investment, focusing first on the within-OLD EMU group (columns (1a) and (1b)), then on the outward foreign investment of OLD EMU in EMU (columns (2a) and (2b)), and finally on the inward foreign investment of OLD EMU by EMU countries (columns (3a) and (3b)). The columns (\#a) and (\#b) report, respectively, the results without and with the interaction of the OLD EMU dummy with the crisis and post-crisis dummies.

Table 3. FPE and OLD EMU

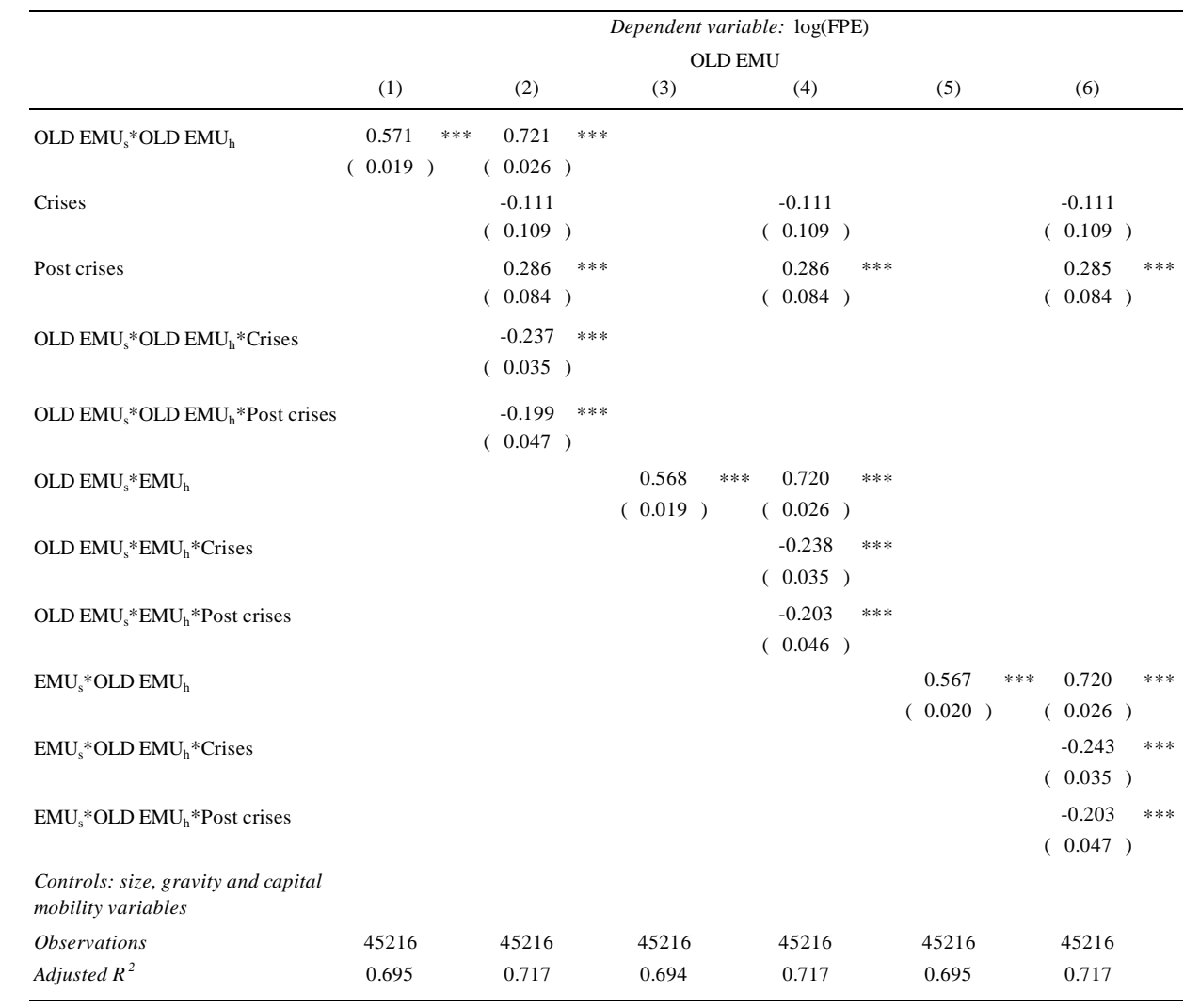

Note. This table reports the results of a Poisson Pseudo Maximum Likelihood regression (Santos Silva and Tenreyro (2006)), as from equation (2) in the main text, with individual country pair fixed-effects and robust standard errors clustered by year. The dependent variable is $\log \left(F P E_{s h}\right)$, where the subscript $s h$ represents the couple investing country $s$-destination country $h$. All controls of Table 2 are included, but not reported. The columns (\#a) and (\#b) consider specifications, respectively, without and with interactions with crisis and post-crisis dummy. Columns (1a) and (1b) consider the investments among OLD EMU countries, columns (2a) and (2b) consider OLD EMU countries investing in EMU host countries, while the columns (3a) and (3b) consider EMU source countries investing in OLD EMU host countries. ***, **, and * indicate significance at the 1,5 , and $10 \%$ levels, respectively.

From column (1a) of Table 3, we observe that the foreign investment within OLD EMU countries is, on the whole time span, more than 77 percent larger than all other bilateral holdings. This effect has been severely flawed by the crisis: in column (1b), we observe that, belonging to the original EMU group used to induce $106 \%$ larger investment, which dropped to a $62 \%$ effect during the crisis and slightly recovered to a $69 \%$ after the crisis. These findings suggest a decisive role of the crisis in loosening the linkages among original EMU countries: even keeping constant the composition of the EMU group, the role of the common currency has drastically shrunk after the crisis.

To detect the contribution of the enlargement, we observe the investment of the OLD EMU countries in the 
whole Euro area and compare it with the behavior observed within the OLD EMU group. Column (2a) shows that OLD EMU investment in EMU economies is 76 percent larger than other bilateral holdings, a figure very close to the one in column (1a). The results in column (2b) show that the change of investment of OLD EMU in the EMU group is almost identical to the one recorded among OLD EMU (column (1b)). While the almost identical figure in the pre-crisis period is predictable, since the EMU group in the pre-crisis period coincides with OLD EMU (with the only exception of Slovenia entering the union in 2007), the identical pattern during and after the crisis is far from obvious (Note 11).

Columns (3a) and (3b) show the investment of the EMU economy in OLD EMU: the 76 percent higher average impact on investment (column (3a)), is the result of a dynamic pattern very close to the one observed among OLD EMU in column (2b). If the enlargement had significantly contributed to the shrinkage of linkages among EMU countries, we should observe a stronger decrease in the investment of OLD EMU in EMU (and of EMU in OLD EMU) than within the OLD EMU sub-group: since it is not the case, the evidence suggests that the lion's share of the drop is attributable to the crisis.

\subsubsection{Robustness}

To provide further consistency to these findings, in Table 4, we undergo our main results to a robustness check on the sample of countries.

For the ease of comparability, we report, in columns (1) to (4) of Table 4, the main findings underlined above. In column (1), we report the results of column (3) of Table 2, while columns (2), (3) and (4) of Table 4 replicate columns (1b), (2b) and (3b) of Table 3.

Table 4. Robustness

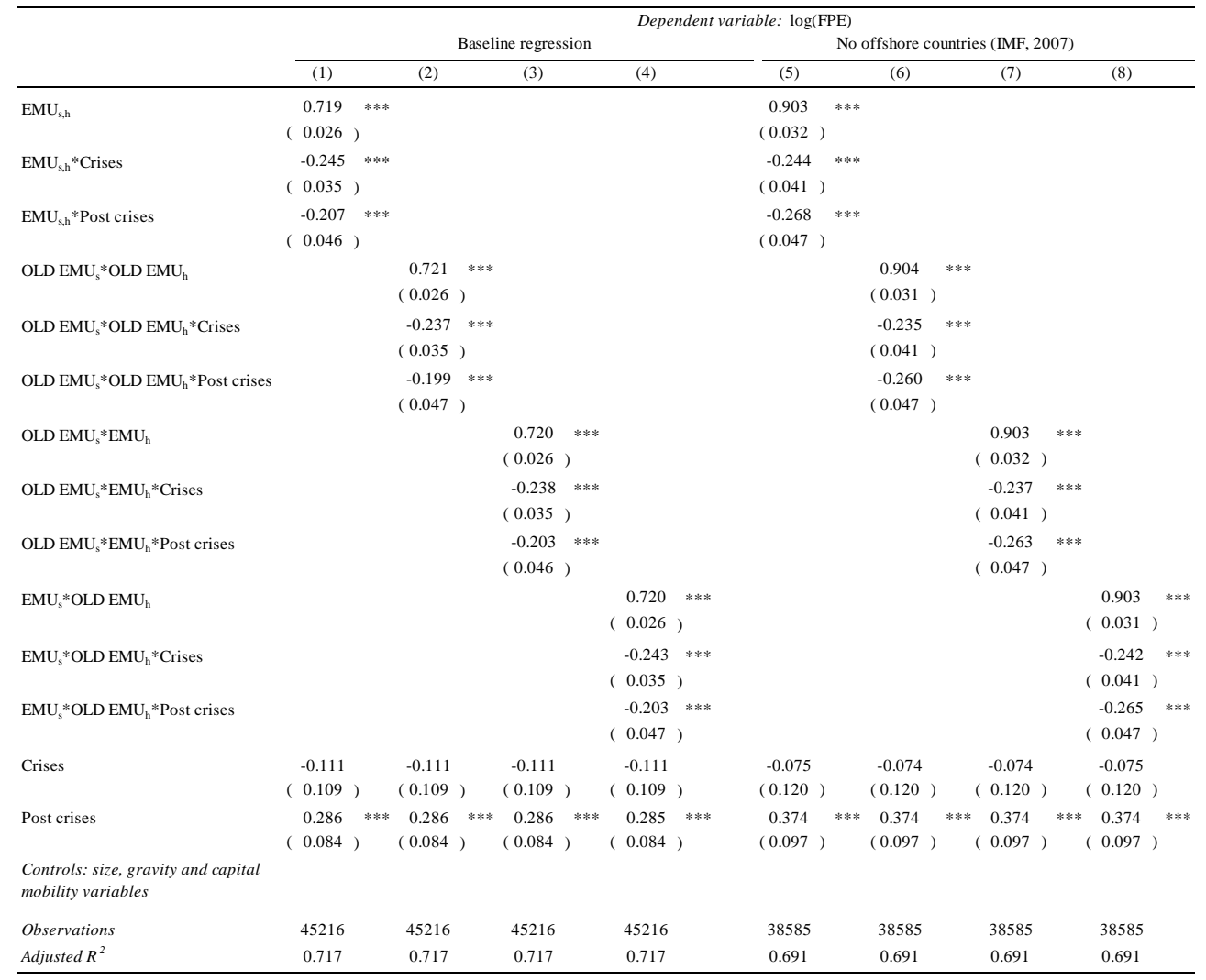

Note. This table reports the results of a Poisson Pseudo Maximum Likelihood regression (Santos Silva and Tenreyro (2006)), as from equation (2) in the main text, with individual country pair fixed-effects and robust standard errors clustered by year. The dependent variable is $\log \left(F P E_{s h}\right)$, where the subscript $s h$ represents the couple investing country $s$-destination country $h$. All controls of Table 2 are included, but not reported. The columns (1) to (4) refer to the baseline estimation adopted in the paper. In column (1) we report the results of column (3) of Table 2, while columns (2) to (4) of Table 4 replicate columns (1b), (2b) and (3b) of Table 3. The columns (5) to (8) replicate the estimates of columns (1) to (4), when the offshore list follows Zoromé (2007). ***,**, and * indicate significance at the 1, 5, and 10\% levels, respectively. 
Columns (5) to (8) of Table 4 report results under a different classification of offshore financial centers: the list of offshore centers excludes the Netherlands, but includes other EMU countries, such as Cyprus, Malta and Latvia, following the classification in Zoromé (2007) (Note 12).

Finally, columns (5) to (8) account for an alternative specification of the crisis period, starting from 2007, rather than from 2008. This final check plays a two-fold role: on the one hand, it represents a sensitivity check on the dates of the crisis; on the other hand, being the enlargement process kicked off by Slovenia in 2007, the redefinition of the pre-crisis period as 2001-2006, allows the pre-crisis and the pre-enlargement period to coincide, and then to better isolate the role of the NEW EMU entry on FPE holdings by OLD EMU.

We find that, under different definition of offshore centers and crisis periods, the results, though different in size, are confirmed: the enlargement seems not to have majorly contributed to worsen the linkages in the Euro area.

Table 5. Summary of the effects of EMU on FPE

\begin{tabular}{|c|c|c|c|c|c|}
\hline & effect & EMU or & n FPE & $\begin{array}{l}\quad(b \\
\text { effect o } \\
\text { on FPE } \\
\text { to pre- } \\
\text { period }\end{array}$ & $\begin{array}{l}\text { ) } \\
\text { f EMU } \\
\text { elative } \\
\text { crisis } \\
(\Delta \%)\end{array}$ \\
\hline & $\begin{array}{c}\text { pre- } \\
\text { crisis }\end{array}$ & crisis & $\begin{array}{l}\text { post- } \\
\text { crisis }\end{array}$ & crisis & $\begin{array}{l}\text { post- } \\
\text { crisis }\end{array}$ \\
\hline & (1) & (2) & (3) & (4) & (5) \\
\hline$\frac{\text { I. Baseline mo }}{\text { (col. (1)-(4), Ta }}$ & & & & & \\
\hline $\mathrm{EMU}_{\mathrm{s}}-\mathrm{EMU}_{\mathrm{h}}$ & $105 \%$ & $61 \%$ & $67 \%$ & $-42 \%$ & $-36 \%$ \\
\hline $\mathrm{OLD}_{\mathrm{s}}-\mathrm{OLD}_{\mathrm{h}}$ & $105 \%$ & $62 \%$ & $68 \%$ & $-41 \%$ & $-36 \%$ \\
\hline $\mathrm{OLD}_{\mathrm{s}}-\mathrm{EMU}_{\mathrm{h}}$ & $105 \%$ & $62 \%$ & $68 \%$ & $-41 \%$ & $-36 \%$ \\
\hline $\mathrm{EMU}_{\mathrm{s}}-\mathrm{OLD}_{\mathrm{h}}$ & $105 \%$ & $61 \%$ & $68 \%$ & $-42 \%$ & $-36 \%$ \\
\hline II. No offshore & & & & & \\
\hline (col. (5)-(8), Ta & & & & & \\
\hline $\mathrm{EMU}_{\mathrm{s}}-\mathrm{EMU}_{\mathrm{h}}$ & $146 \%$ & $83 \%$ & $88 \%$ & $-43 \%$ & $-40 \%$ \\
\hline $\mathrm{OLD}_{\mathrm{s}}-\mathrm{OLD}_{\mathrm{h}}$ & $146 \%$ & $85 \%$ & $89 \%$ & $-42 \%$ & $-39 \%$ \\
\hline $\mathrm{OLD}_{\mathrm{s}}-\mathrm{EMU}_{\mathrm{h}}$ & $146 \%$ & $84 \%$ & $89 \%$ & $-42 \%$ & $-39 \%$ \\
\hline $\mathrm{EMU}_{\mathrm{s}}-\mathrm{OLD}_{\mathrm{h}}$ & $146 \%$ & $83 \%$ & $89 \%$ & $-43 \%$ & $-39 \%$ \\
\hline $\begin{array}{l}\text { III. No offshor } \\
\text { (col. (1)-(4), Ta }\end{array}$ & & & & & \\
\hline $\mathrm{EMU}_{\mathrm{s}}-\mathrm{EMU}_{\mathrm{h}}$ & $147 \%$ & $93 \%$ & $89 \%$ & $-36 \%$ & $-40 \%$ \\
\hline $\mathrm{OLD}_{\mathrm{s}}-\mathrm{OLD}_{\mathrm{h}}$ & $147 \%$ & $95 \%$ & $90 \%$ & $-35 \%$ & $-38 \%$ \\
\hline $\mathrm{OLD}_{\mathrm{s}}-\mathrm{EMU}_{\mathrm{h}}$ & $147 \%$ & $95 \%$ & $90 \%$ & $-35 \%$ & $-39 \%$ \\
\hline $\mathrm{EMU}_{\mathrm{s}}-\mathrm{OLD}_{\mathrm{h}}$ & $147 \%$ & $94 \%$ & $89 \%$ & $-36 \%$ & $-39 \%$ \\
\hline$\frac{\text { IV. Alternative }}{\text { (col. (5)-(8), Ta }}$ & & & & & \\
\hline $\mathrm{EMU}_{\mathrm{s}}-\mathrm{EMU}_{\mathrm{h}}$ & $110 \%$ & $68 \%$ & $67 \%$ & $-38 \%$ & $-39 \%$ \\
\hline $\mathrm{OLD}_{\mathrm{s}}-\mathrm{OLD}_{\mathrm{h}}$ & $110 \%$ & $69 \%$ & $68 \%$ & $-37 \%$ & $-38 \%$ \\
\hline $\mathrm{OLD}_{\mathrm{s}}-\mathrm{EMU}_{\mathrm{h}}$ & $110 \%$ & $69 \%$ & $67 \%$ & $-37 \%$ & $-39 \%$ \\
\hline $\mathrm{EMU}_{\mathrm{s}}-\mathrm{OLD}_{\mathrm{h}}$ & $110 \%$ & $68 \%$ & $67 \%$ & $-38 \%$ & $-39 \%$ \\
\hline
\end{tabular}

Note. This table reports a summary of the results two specifications in Table 4 (I. Baseline model and II. No offshore (IMF, 2007)) and 4A in Appendix B (III. No offshore (L\&M-F, 2017) and IV. Alternative Crisis period (2007-2012)). Columns (1) to (3) report the marginal effect of the dummy variable at the head of the rows on FPE. The marginal effect, in percentage terms, is obtained as follows: ( $\left.\mathrm{e}^{\beta}-1\right) \cdot 100$, where $\beta$ is the coefficient reported in Tables 4/4A. Columns (4) and (5) report, for the dummies at the head of the rows, the change in the marginal effects, respectively, in the crisis period and in the post crisis period, relatively to the pre-crisis period.

\section{The Role of Crisis and Enlargement}

The above-discussed results suggest that the crisis and its lasting aftermaths are mainly responsible of the drop of bilateral FPE in the Euro area. In Table 5, we summarize the quantitative assessment of this shrinkage.

The figures in Table 5 are computed from Tables 4 and 4A (Appendix B). The first panel refers to the baseline specification in Table 4 (columns (1) to (4)), the second to the alternative offshore center specification in Table 4 (columns (5) to (8)), while the third and fourth panel are based on the robustness specifications in Table 4A. 
Columns (1) to (3) of Table 5 form the block (a), and report the marginal effect of the common currency on bilateral FPE, in the pre-crisis, crisis and after crisis periods. The marginal effect, in percentage terms, is obtained as follows: $\left(\mathrm{e}^{\beta}-1\right) \cdot 100$, where $\beta$ is the coefficient reported in Tables 4/4A. As an illustrative example, we take the first row of the first panel. Column (1) of Table 4 reports a coefficient of the $E M U_{s h}$ in the excluded period, i.e., the pre-crisis period, equal to 0.719. Since the dependent variable is defined in log terms, this coefficient implies that EMU members invest one another $105 \%$ more than other countries $\left(\mathrm{e}^{0.719}-1=1.05\right)$ (Note 13). The coefficient of the EMU dummy in the crisis period is equal to the coefficient of the interaction term plus the coefficient of the "pure" EMU dummy, that is, the coefficient the excluded (pre-crisis) period. It is therefore $0.474(=0.719-0.245)$, and the effect on FPE is $\mathrm{e}^{0.474}-1=0.61$, that is, EMU countries during the crisis invest one another $61 \%$ more than other countries. Finally, in the post-crisis period the 0.512 coefficient translates into a $67 \%$ $\left(\mathrm{e}^{0.512}-1=0.67\right)$ higher investment of EMU countries relative to other countries.

The second, third and fourth row of the same panel, report the effect of the common currency (as shown in columns (2) to (4) of Table 4), restricting to OLD EMU investing in OLD EMU, OLD EMU investing in all EMU, and all EMU investing in OLD EMU, respectively.

This block (a) of Table 5 provides a consistent: the currency effect on bilateral FPE has significantly decreased after the crisis period and has not significantly recovered after the crisis.

Columns (4) and (5) of Table 5 form the block (b), and report the variation (in \%) of the EMU effect in crisis and post-crisis, relative to the pre-crisis period. For instance, the first line of the (b) block shows that the bilateral FPE among EMU members has fallen by $42 \%((61 \%-105 \%) / 105 \%)$ in the crisis period and by $36 \%$ in the post-crisis period. This block (b) provides a picture of the evolution over time of the EMU linkage in the whole EMU group (first row), and in its sub-groups (second, third, and fourth rows).

Interestingly, though the level of the coefficients, and consequently the effects on FPE, may differ across different specifications (as shown in block (a)), the percentages in block (b) of Table 5 are instead very similar in size and pattern across the four panels.

We observe, first, that across different specifications, the drop in the EMU effect is not different from the drop within OLD EMU countries. Second, the size of the drop is around 40\%. Third, the magnitude of the drop in the post-crisis period is not significantly different from the one observed in the crisis period.

These findings suggest the following: the significant drop in integration in the Euro area has been triggered by the crisis, whose effects are large and persistent. Indeed, both the size of the coefficients (block (a)) and their change (block (b)) among OLD EMU are not different from the ones between OLD EMU and all EMU (and the ones among all EMU countries). It underlines the still marginal contribution of the NEW EMU to the evolution of the aggregate EMU group: the enlargement has neither worsened nor alleviated the fall.

Does it imply that the enlargement process has played no role at all in the integration of foreign portfolio investments in the Euro Area?

The regression estimates in Table 6 investigate the investment patterns of the NEW EMU countries, i.e., those countries acquiring the status of NEW EMU members after joining the union.

In columns (1) and (2) of Table 6, we investigate the role of the common currency in shaping the FPE between NEW EMU and the whole group of EMU countries. We observe that NEW EMU countries invest in the whole euro area $47 \%$ less than other country pairs $\left(\mathrm{e}^{-0.634}-1=-0.47\right.$, column $\left.(1)\right)$, and that receive $24 \%$ lower investment from the whole euro area (column (2)).

When considering separately the two groups, NEW EMU and OLD EMU, we observe that NEW EMU invest in OLD EMU 49 percent less than other country pairs $\left(\mathrm{e}^{-0.680}-1=-0.49\right.$, column (3)) and OLD EMU invest in NEW EMU 27 percent less than other country pairs (column (4)). Since the cross group investments are significantly lower than the corresponding holdings for the whole EMU area, the investments among NEW EMU must be larger, so that the average - inward or outward-EMU holdings improve when including them. Indeed, the investment among NEW EMU countries are about 1.65 times larger than other country pairs (column (5)).

While we can control for the role of the crisis and post-crisis periods on FPE (as we do in Table 6), unfortunately we are not able to apply the standard Difference-in-Difference approach to NEW EMU (through the interaction with crisis and post crisis dummies), because NEW EMU were not such before the crisis. 
Table 6. FPE and NEW EMU

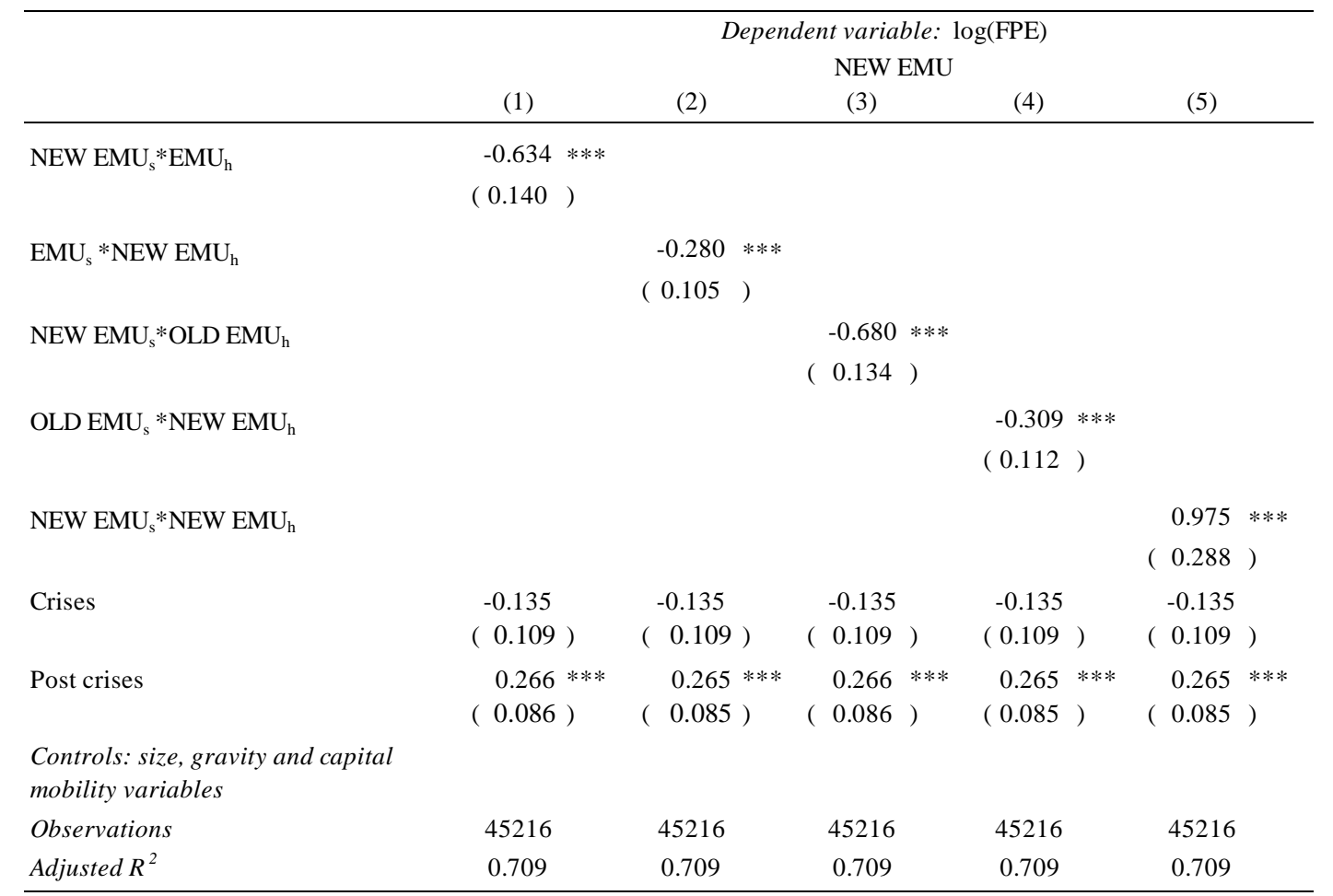

Note. This table reports the results of a Poisson Pseudo Maximum Likelihood regression (Santos Silva and Tenreyro (2006)), as from equation (2) in the main text, with individual country pair fixed-effects and robust standard errors clustered by year. The dependent variable is $\log \left(F P E_{\text {sh }}\right)$, where the subscript $s h$ represents the couple investing country $s$-destination country $h$. All controls of Table 2 are included, but not reported. The columns (1) and (2) consider the investment patterns between NEW EMU and the whole group of EMU countries (OLD EMU and NEW EMU), while columns (3) and (4) replicate the same analysis when considering the investment patterns between NEW EMU and OLD EMU. Finally, columns (5) considers the investment patterns among NEW EMU. When referring to NEW EMU, we consider the associated dummy equal to 1 only at the time of entry (and thereafter) of the country in the union. ***, **, and * indicate significance at the 1,5 , and $10 \%$ levels, respectively.

We can nevertheless draw useful information from the observation of the evolution of the investment patterns of the New countries: we apply this label to those countries joining the union after the enlargement process, regardless of their timing of entry. This implies that we examine the evolution of new members' inward and outward FPE, from 2001 to 2017, including, for instance, for all years, Slovenia and Lithuania, though the former joined the union in 2007, while the latter entered in 2015.

In Table 7, we consider the inward and outward investment of New countries in the euro area. The columns (\#a) and (\#b) consider specifications, respectively, without and with interactions of the EMU dummy with crisis and post-crisis dummies.

Columns (1a) and (1b) show that on average New countries underweight equities issued by EMU countries in their portfolios: their bilateral investment in the Euro Area are indeed half of other country pairs' FPE $\left(\mathrm{e}^{-0.704}-1=-0.51\right.$, column (1a)). Interestingly, this outcome is the result of a larger negative position before the crisis and a noticeable improvement afterwards (from 78\% lower FPE before the crisis, to $60 \%$ lower FPE during the crisis, to $33 \%$ lower FPE after the crisis). Columns (2a) and (2b) show that the euro area as a whole also underweights on average equities issued by New countries, though at a lower extent (30\% lower FPE, relative to other country pairs), but this underweighting has not significantly decreased over time.

Recalling that the enlargement process started in 2007, these findings suggest an asymmetrical process of integration of New countries in the euro area after the enlargement: they have increased their outward investment in the euro area, but have not benefited a similar inward investment from EMU members. 
Table 7. FPE and New countries

\begin{tabular}{|c|c|c|c|c|c|c|c|c|c|c|c|}
\hline & & & & & Depend & lent va & riable: $\log (\mathrm{FPI}$ & & & & \\
\hline & & & & & & New & countries & & & & \\
\hline & (1a) & (1b) & (2a) & (2b) & (3a) & & (3b) & (4a) & (4b) & (5a) & (5b) \\
\hline New countrys $* \mathrm{EMU}_{\mathrm{h}}$ & $\begin{array}{l}-0.704 * * * \\
(0.096)\end{array}$ & $\begin{array}{l}-1.526 * * * \\
(0.147)\end{array}$ & & & & & & & & & \\
\hline New countrys $* \mathrm{EMU}_{\mathrm{h}} *$ Crises & & $\begin{array}{l}0.613 * * * \\
(0.138)\end{array}$ & & & & & & & & & \\
\hline New country ${ }_{\mathrm{s}}{ }^{*} \mathrm{EMU}_{\mathrm{h}}{ }^{*}$ Post crises & & $\begin{array}{l}1.120 * * * \\
(0.150)\end{array}$ & & & & & & & & & \\
\hline $\mathrm{EMU}_{\mathrm{s}} *$ New country & & & $\begin{array}{l}-0.350 * * * \\
(0.084)\end{array}$ & $\begin{array}{r}-0.473 * \\
(0.242)\end{array}$ & & & & & & & \\
\hline EMU $_{\mathrm{s}} *$ New country $*$ Crises & & & & $\begin{array}{c}0.272 \\
(0.267)\end{array}$ & & & & & & & \\
\hline $\mathrm{EMU}_{\mathrm{s}} *$ New country $*$ Post crises & & & & $\begin{array}{l}0.100 \\
(0.289)\end{array}$ & & & & & & & \\
\hline New country ${ }_{\mathrm{s}}{ }^{\circ} \mathrm{OLD} \mathrm{EMU}_{\mathrm{h}}$ & & & & & $\begin{array}{r}-0.770 \\
(0.094\end{array}$ & & $\begin{array}{l}-1.527 * * * \\
(0.147)\end{array}$ & & & & \\
\hline New country $* \mathrm{OLD} \mathrm{EMU}_{\mathrm{h}} *$ Crises & & & & & & & $\begin{array}{l}0.5511^{* * * *} \\
(0.130)\end{array}$ & & & & \\
\hline New country $_{\mathrm{s}}{ }^{*}$ OLD EMU ${ }_{\mathrm{h}}{ }^{*}$ Post crises & & & & & & & $\begin{array}{l}1.049^{* * * *} \\
(0.154)^{*}\end{array}$ & & & & \\
\hline OLD EMU $_{\mathrm{s}} *$ New country & & & & & & & & $\begin{array}{l}-0.374 * * * \\
(0.085)\end{array}$ & $\begin{array}{r}-0.473 * \\
(0.242)\end{array}$ & & \\
\hline OLD EMU $_{\mathrm{s}} *$ New country ${ }_{\mathrm{h}}$ *Crises & & & & & & & & & $\begin{array}{c}0.268 \\
(0.268)\end{array}$ & & \\
\hline $\mathrm{OLD} \mathrm{EMU}_{\mathrm{s}} *$ New country ${ }_{\mathrm{h}} *$ Post crises & & & & & & & & & $\begin{array}{c}0.046 \\
(0.296)\end{array}$ & & \\
\hline New countrys ${ }^{*}$ New country & & & & & & & & & & $\begin{array}{l}1.375 * * * \\
(0.154)\end{array}$ & $\left.\begin{array}{l}1.432 \\
(0.386\end{array}\right)$ \\
\hline New country $*$ New country ${ }_{\mathrm{h}} *$ Crises & & & & & & & & & & & $\begin{array}{c}-0.140 \\
(0.412)\end{array}$ \\
\hline New country ${ }_{\mathrm{s}} *$ New country ${ }_{\mathrm{h}} *$ Post crises & & & & & & & & & & & $\begin{array}{l}-0.023 \\
(0.393)\end{array}$ \\
\hline Crises & $\begin{array}{c}-0.135 \\
(0.109)\end{array}$ & $\begin{array}{l}-0.135 \\
(0.109)\end{array}$ & $\begin{array}{c}-0.135 \\
(0.109)\end{array}$ & $\begin{array}{l}-0.136 \\
(0.109)\end{array}$ & $\begin{array}{r}-0.135 \\
(0.109\end{array}$ & & $\begin{array}{c}-0.135 \\
(0.109)\end{array}$ & $\begin{array}{c}-0.135 \\
(0.109)\end{array}$ & $\begin{array}{c}-0.136 \\
(0.109)\end{array}$ & $\begin{array}{l}-0.135 \\
(0.109)\end{array}$ & $\begin{array}{c}-0.135 \\
(0.109)\end{array}$ \\
\hline Post crises & $\begin{array}{l}0.265 * * * \\
(0.086)\end{array}$ & $\begin{array}{l}0.265 \text { **** } \\
(0.086)\end{array}$ & $\left.\begin{array}{l}0.265 \\
(0.085)\end{array}\right)^{*}$ & $\begin{array}{l}0.265 * * * \\
(0.085)\end{array}$ & $\begin{array}{l}0.266 \\
(0.086\end{array}$ & **** & $\begin{array}{l}0.265 \text { **** } \\
(0.086)\end{array}$ & $\begin{array}{l}0.265)^{* * * *} \\
(0.085)^{-1}\end{array}$ & $\begin{array}{l}0.2655^{* * * *} \\
(0.085)\end{array}$ & $\left(0.2655^{* * * *}\right.$ & $\begin{array}{l}0.265 * * * \\
(0.085)\end{array}$ \\
\hline $\begin{array}{l}\text { Controls: size, gravity and capital } \\
\text { mobility variables }\end{array}$ & & & & & & & & & & & \\
\hline Observations & 45216 & 45216 & 45216 & 45216 & 45216 & & 45216 & 45216 & 45216 & 45216 & 45216 \\
\hline Adjusted $R^{2}$ & 0.709 & 0.709 & 0.709 & 0.709 & 0.709 & & 0.709 & 0.709 & 0.709 & 0.709 & 0.709 \\
\hline
\end{tabular}

Note. This table reports the results of a Poisson Pseudo Maximum Likelihood regression (Santos Silva and Tenreyro (2006)), as from equation (2) in the main text, with individual country pair fixed-effects and robust standard errors clustered by year. The dependent variable is $\log \left(F P E_{\text {sh }}\right)$, where the subscript $s h$ represents the couple investing country $s$-destination country $h$. All controls of Table 2 are included, but not reported. The columns (\#a) and (\#b) consider specifications, respectively, without and with interactions with crisis and post-crisis dummy. Columns (1a) to (2b) consider the investment patterns between New countries and the whole EMU group (OLD EMU and NEW EMU). Columns (3a) to (4b) replicate the same analysis when considering the investment patters between OLD EMU and New countries. Finally, columns (4a) and (4b) consider the investment patterns among New countries. To estimate the change in investment patterns of New countries, we consider the associated dummy equal to 1 at any point in time, regardless of the time of entry of the new country in the union. $* * *, * *$, and $*$ indicate significance at the 1,5 , and $10 \%$ levels, respectively.

The observed effects reflect averages: this could hide different group-specific dynamics, which we try to seize by considering, separately, the investment patterns among New countries, and between New countries and OLD EMU.

Column (3a) and (3b) show that the bilateral FPE of New countries in OLD EMU are significantly lower than other country pairs', but these negative positions have significantly improved over time: starting from a heavy negative position (-78\%), the linkages improved during and after the crisis, thus halving the initial disadvantage $(-38 \%)$.

When considering OLD EMU investing in New countries, we observe that the average effect is negative (column (4a)) as OLD EMU invest in New countries 30\% less than other countries invest one another, but this effect has neither improved nor worsened over time (column (4b)). These findings underline that OLD EMU used to underweight New countries in their foreign portfolios before 2007, and that the enlargement process has not improved this situation. Interestingly, the evidence that OLD EMU have not altered their investments in New countries over time also dispels any doubt on the hypothesis of diversion of OLD EMU countries' investments 
from OLD EMU to New countries destination economies during and after the crisis period.

Finally, in columns (5a) and (5b), we consider the investment pattern among New countries. We find that, on average, their linkages are very strong: they invest one another almost 3 times more than other country pairs (column (5a)), and these strong linkages have remained fairly stable over time (column (5b)).

Table 8. Descriptive statistics split by OLD and NEW EMU

\begin{tabular}{|c|c|c|c|c|c|c|c|}
\hline & \multicolumn{7}{|c|}{ Descriptive Statistics EMU, OLD EMU, New EMU } \\
\hline & Min & 1st Qu & Median & Mean & 3rd Qu & Max & St. dev \\
\hline & \multicolumn{7}{|c|}{ I. $E M U$} \\
\hline \multicolumn{8}{|l|}{$\underline{\text { Size variables }}$} \\
\hline GDP per cap (US \$) & 11729.00 & 23196.00 & 32763.00 & 37229.00 & 45703.00 & 119225.00 & 20075.20 \\
\hline GDP (US \$) & $8.53 \mathrm{E}+09$ & $8.95 \mathrm{E}+10$ & $2.66 \mathrm{E}+11$ & $7.53 \mathrm{E}+11$ & $1.07 \mathrm{E}+12$ & $3.89 \mathrm{E}+12$ & $9.83 \mathrm{E}+11$ \\
\hline Market cap (US \$) & $4.93 \mathrm{E}+08$ & $2.73 \mathrm{E}+10$ & $8.29 \mathrm{E}+10$ & $3.18 \mathrm{E}+11$ & $5.71 \mathrm{E}+11$ & $1.29 \mathrm{E}+12$ & $4.09 \mathrm{E}+11$ \\
\hline \multicolumn{8}{|l|}{ Institutional variables } \\
\hline Rule of Law & 56.70 & 81.70 & 88.90 & 86.77 & 95.20 & 100.00 & 10.31 \\
\hline Govt. Effectiveness & 60.20 & 80.10 & 88.80 & 86.47 & 93.60 & 100.00 & 9.19 \\
\hline Regulatory quality & 59.10 & 80.30 & 87.75 & 87.06 & 94.20 & 99.50 & 8.59 \\
\hline Control of Corruption & 52.40 & 77.70 & 89.00 & 84.35 & 93.40 & 100.00 & 12.14 \\
\hline Perceived Control of Corruption & 33.90 & 58.78 & 70.00 & 68.53 & 80.00 & 99.00 & 14.65 \\
\hline \multicolumn{8}{|l|}{ II. $O L D E M U$} \\
\hline \multicolumn{8}{|l|}{$\overline{\text { Size variables }}$} \\
\hline GDP per cap (US \$) & 11729.00 & 27270.00 & 38911.00 & 41348.00 & 47983.00 & 119225.00 & 20541.76 \\
\hline GDP (US \$) & $2.13 \mathrm{E}+10$ & $2.32 \mathrm{E}+11$ & 4.10E+11 & $9.42 \mathrm{E}+11$ & $1.48 \mathrm{E}+12$ & $3.89 \mathrm{E}+12$ & $1.03 \mathrm{E}+12$ \\
\hline Market cap (US \$) & $2.73 \mathrm{E}+10$ & $7.15 \mathrm{E}+10$ & $2.06 \mathrm{E}+11$ & $4.02 \mathrm{E}+11$ & $5.88 \mathrm{E}+01$ & $1.29 \mathrm{E}+12$ & $4.22 \mathrm{E}+11$ \\
\hline \multicolumn{8}{|l|}{ Institutional variables } \\
\hline Rule of Law & 56.70 & 84.10 & 90.75 & 88.26 & 96.20 & 100.00 & 10.59 \\
\hline Govt. Effectiveness & 60.20 & 82.83 & 91.30 & 87.82 & 94.33 & 100.00 & 9.65 \\
\hline Regulatory quality & 59.10 & 81.25 & 91.00 & 88.16 & 95.70 & 99.50 & 8.77 \\
\hline Control of Corruption & 52.40 & 82.50 & 90.90 & 86.59 & 94.45 & 100.00 & 12.12 \\
\hline Perceived Control of Corruption & 33.90 & 63.00 & 74.00 & 71.17 & 82.00 & 99.00 & 15.02 \\
\hline \multicolumn{8}{|l|}{ III. NEW EMU } \\
\hline \multicolumn{8}{|l|}{ Size variables } \\
\hline GDP per cap (US \$) & 13640.00 & 17422.00 & 21788.00 & 21669.00 & 24634.00 & 35391.00 & 5024.66 \\
\hline GDP (US \$) & $8.53 \mathrm{E}+09$ & $2.26 \mathrm{E}+10$ & $2.75 \mathrm{E}+10$ & $3.96 \mathrm{E}+10$ & $4.88 \mathrm{E}+10$ & $1.01 \mathrm{E}+11$ & $2.75 \mathrm{E}+10$ \\
\hline Market cap (US \$) & $4.93 \mathrm{E}+08$ & $1.41 \mathrm{E}+09$ & $1.67 \mathrm{E}+09$ & $2.41 \mathrm{E}+09$ & $3.18 \mathrm{E}+09$ & $5.60 \mathrm{E}+09$ & $1.75 \mathrm{E}+09$ \\
\hline \multicolumn{8}{|l|}{ Institutional variables } \\
\hline Rule of Law & 64.80 & 80.30 & 82.40 & 81.14 & 86.40 & 91.80 & 6.63 \\
\hline Gov Effectiveness & 73.90 & 78.20 & 81.15 & 81.37 & 83.90 & 92.40 & 4.39 \\
\hline Regulatory quality & 72.10 & 78.20 & 82.70 & 82.87 & 88.30 & 93.30 & 6.29 \\
\hline Control of Corruption & 60.10 & 70.20 & 77.80 & 75.87 & 81.00 & 88.90 & 7.64 \\
\hline Perceived Control of Corruption & 39.70 & 55.23 & 58.85 & 58.56 & 63.38 & 71.00 & 7.00 \\
\hline
\end{tabular}

Note. This table reports the descriptive statistics of size and institutional variables used in the analysis, relative to EMU, OLD EMU and NEW EMU countries. The subscript * indicates that the corresponding variable is included in the analysis for both the destination and the investing country.

From Table 6 and 7, we have learnt the following insights: first, OLD EMU and new members are reciprocally underweighted in their foreign portfolios; second, the linkages among new members are quite strong. New countries in fact provide signals of integration: the underweighting positions of New countries in OLD EMU have improved after the enlargement, and the strong linkages among New countries are kept solid even in crisis periods. This evidence confirms, for the EMU enlargement and for portfolio equities markets, the evidence previously documented in the literature relative to UE enlargement (Baltzer et al., 2008) and fixed securities markets (Lane \& Milesi-Ferretti, 2017). The integration path has not been symmetrical, because the OLD EMU kept similarly underweighting New countries' equities after the enlargement.

From Table 5, we observed that the entry of new members has not affected the average linkages among EMU members: the evolution within the whole EMU area is almost identical to the evolution among OLD EMU. The negligible impact of the enlargement on the impact of the overall EMU dummy implies that the positive contribution provided by the strong linkages among New countries has been offset by the negative contribution 
provided by the weak cross-group linkages (OLD EMU-NEW EMU). Indeed, New countries underwent a process of integration in the Euro area by increasing their investments in OLD EMU, but nevertheless they still keep underweighting them; the OLD EMU kept underweighting New countries' equities in their portfolios, before and after the enlargement, by same extent.

In the following section, we investigate which peculiar features of OLD EMU and/or New countries might have potentially hindered the integration process.

\section{Interpretation of Findings: The Role of Size and Institutions}

In this section, we try to understand if the exceptional drop in bilateral investments in the Euro area can be due to the evolution of EMU countries' key features, such as economic development and country governance factors.

In Table 8, we report some descriptive statistics of variables capturing economic and financial development ("Size"), and indexes of country governance ("Institutions"), for EMU countries, split in OLD and NEW.

We observe that there is an evident cross-sectional difference between OLD EMU and NEW EMU, both in terms of economic development and in terms of country governance. Relative to the new entrants, OLD EMU countries show a larger market capitalization, GDP per capita and GDP (in US\$). Similarly, OLD EMU countries also show a better performance in country governance, as measured by control of corruption (effective or perceived), rule of law, regulation, and government effectiveness.

On the one hand, the global financial crisis and the subsequent sovereign debt crisis in Europe might have contributed to weaken the linkages among the original EMU members, by producing an unprecedented drop in economic and financial development, and a serious worsening of country governance and stability. On the other hand, the enlargement to countries with a lower average economic size and weaker country governance standards, might explain why the OLD EMU kept underweighting these new members' assets in their portfolios, thus contributing to the evidence of a lower integration in the whole Euro area.

\subsection{Size}

In Table 9, we include the interaction of the EMU dummy with the size variables, to check whether the change in the economic size of EMU countries can be addressed as responsible of the decline in bilateral FPE among EMU countries.

We adopt the Difference-in-Difference strategy implemented so far, and include a regressor equal to 1 if the economic size of the source/host country is "High", that is, above the median ("H_size"), and 0 otherwise. While its coefficient provides a measure of the responsiveness of bilateral FPE to the upper median size of countries for non-EMU country-pairs, the coefficient of the interaction between the upper median dummy and the EMU dummy captures instead the additional role played by larger countries on the FPE of EMU country pairs (Note 14).

The (\#a) columns of Table 9 show the results when considering the interaction of the EMU dummy with the upper median size of the source country, while the (\#b) columns report the findings when the EMU dummy is interacted with the upper median size of the host economies.

Let us consider first the impact of GDP per capita, a measure of the country's standards of living. On the investing side, richer countries invest five times more than other countries, but this effect is not significantly different for EMU countries (column (1a)). On the destination side, instead, we observe that EMU countries above the median in terms of GDP per capita attract 55\% more FPE from other EMU countries, while EMU countries with below the median GDP per capita attract 52 percent lower Euro investment (column (1b)). These findings are consistent with both a decline in bilateral FPE in the Euro area, due to a decrease in GDP per capita among OLD EMU, and the joining of economically less developed new members.

Columns (2a) and (2b) of Table 9 show that the size of the investing economy, as measured by the GDP in US\$, plays a general negative role on bilateral FPE, while the size of the destination economy plays a positive role. While there is no differential impact of the size of the destination EMU country on the FPE in the euro area (column (2b)), the size of the investing EMU country matters: if the EMU investing country has a size (GDP US\$) below the median, it invests in other EMU countries 2.5 times more than other country pairs $\left(\mathrm{e}^{1.259}-1=2.52\right.$, column (2b)), while an investing EMU countries with a upper median GDP US\$ invests in EMU countries only $29 \%$ more than other country pairs $\left(\mathrm{e}^{1.259-1.004}-1=0.29\right.$, column $\left.(2 \mathrm{a})\right)$.

Finally, when considering the stock market capitalization as a measure of financial development, we observe that above the median market capitalization generally induces very large outward and inward investments (columns (3a) and (3b)). 
Table 9. FPE and size factors

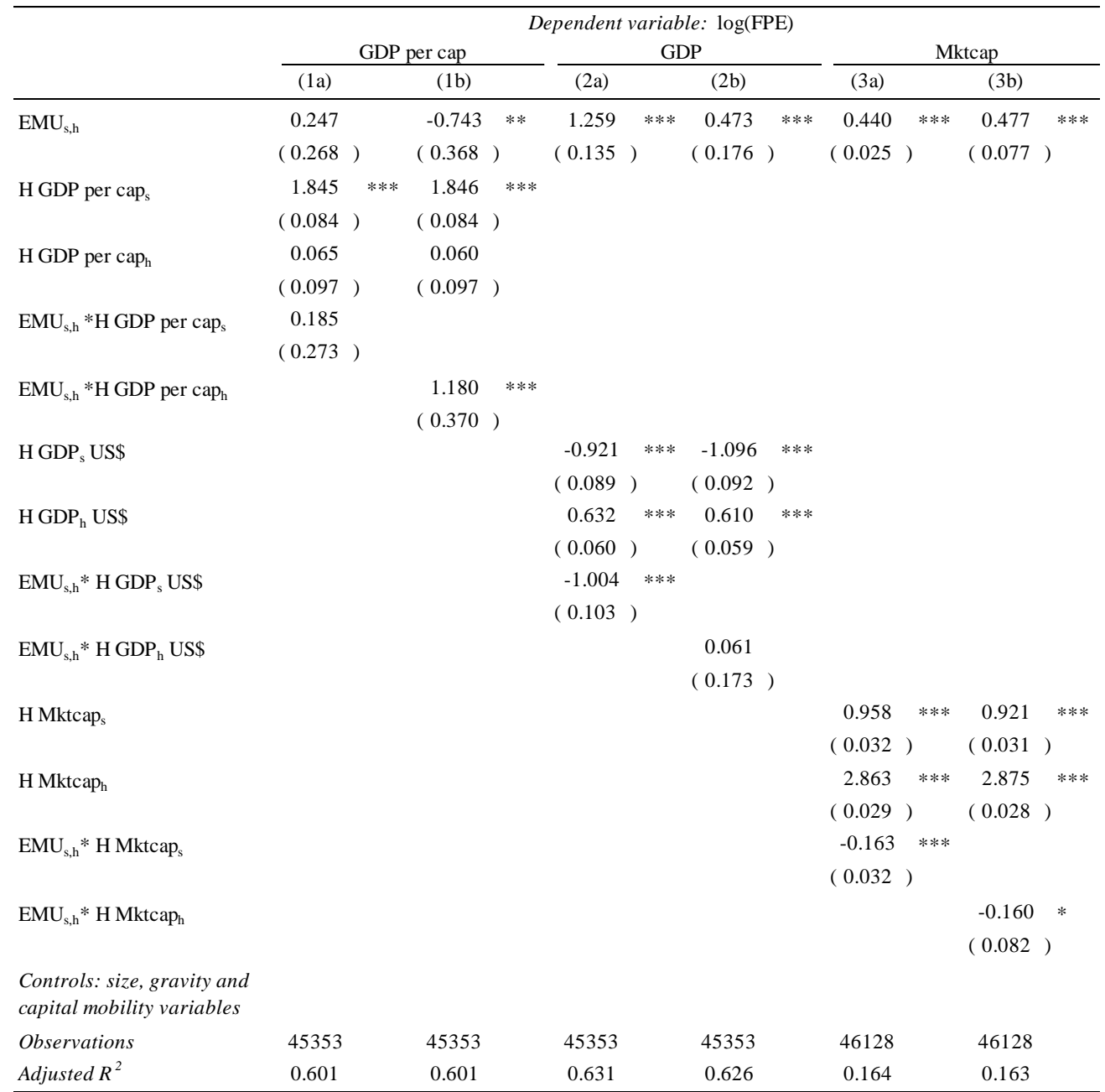

Note. This table reports the results of a Poisson Pseudo Maximum Likelihood regression (Santos Silva and Tenreyro (2006)), as from equation (2) in the main text, with individual country pair fixed-effects and robust standard errors clustered by year. The dependent variable is $\log \left(F P E_{\text {sh }}\right)$, where the subscript $s h$ represents the couple investing country $s$-destination country $h$. All controls of Table 2 are included, but not reported. This table considers the interaction of the bilateral EMU dummy $E M U_{s h}$ with the three measures of size adopted in the paper, two time-varying (GDP per capita, GDP) and one time-invariant (market capitalization). The letter $H$ placed before the size variable stands for "High", and indicates a dummy variable equal to 1 if the corresponding size variable is above the median, and 0 otherwise. Columns (\#a) consider the size variables relative to the source countries, while columns (\#b) consider the size variables relative to the host countries. ***, $* *$, and $*$ indicate significance at the 1,5 , and $10 \%$ levels, respectively.

When looking specifically at the impact on EMU countries, we observe that market capitalization adversely affects EMU linkages: EMU countries with a market capitalization below the median invests one another about $60 \%$ more than other country pairs, while EMU countries with a market capitalization above the median invest one another only about 35\% more. It is worth emphasizing that the dynamics of stock market capitalization are purely cross-sectional, as we include its (time-invariant) 2001 value in all regressions. Our choice is dictated by a standard concern of endogeneity, due to the simultaneity between the total supply of stocks and the level of bilateral investment (demand).

The results about the effect of size on the EMU effect are controversial. The ones relative to the size of the economy (GDP in US\$) and of its financial sector (stock market capitalization) suggest that the EMU effect should be stronger for those member economies relatively smaller. In other words, the cross-sectional enlargement of the union to smaller countries and/or the eventual time-varying contraction in economic and financial development of old members should be conducive of larger bilateral FPE in the Euro area. Conversely, the GDP per capita measure conveys the opposite message: a lower GDP per capita, that is, a lower average standard of living, is associated with lower attractiveness and then lower FPE in the Euro area. 
The evidence of a strong decline in bilateral investment in the Euro area suggests the balance of these contrasting forces: if these measures of size have had an effect on EMU's FPE, then the strength of GDP per capita must have been prevailing. The decrease in wealth (GDP per capita) of EMU countries, making them less attractive, has contributed to reduce bilateral investment in the Euro area. Conversely, the decrease in size (GDP in US\$ or stock market capitalization) of the investing economies, operating in the opposite direction, might only have partially offset the fall in FPE in the euro area.

In Figure 2, we report the dynamics of GDP per capita, the candidate size measure, which, according to the results in Table 9, has potentially contributed to dampen FPE investment among EMU countries (Note 15). In panel a) we represent the evolution of GDP per capita over time for EMU and OLD EMU, while panel b) shows the evolution for NEW EMU and New countries (Note 16).

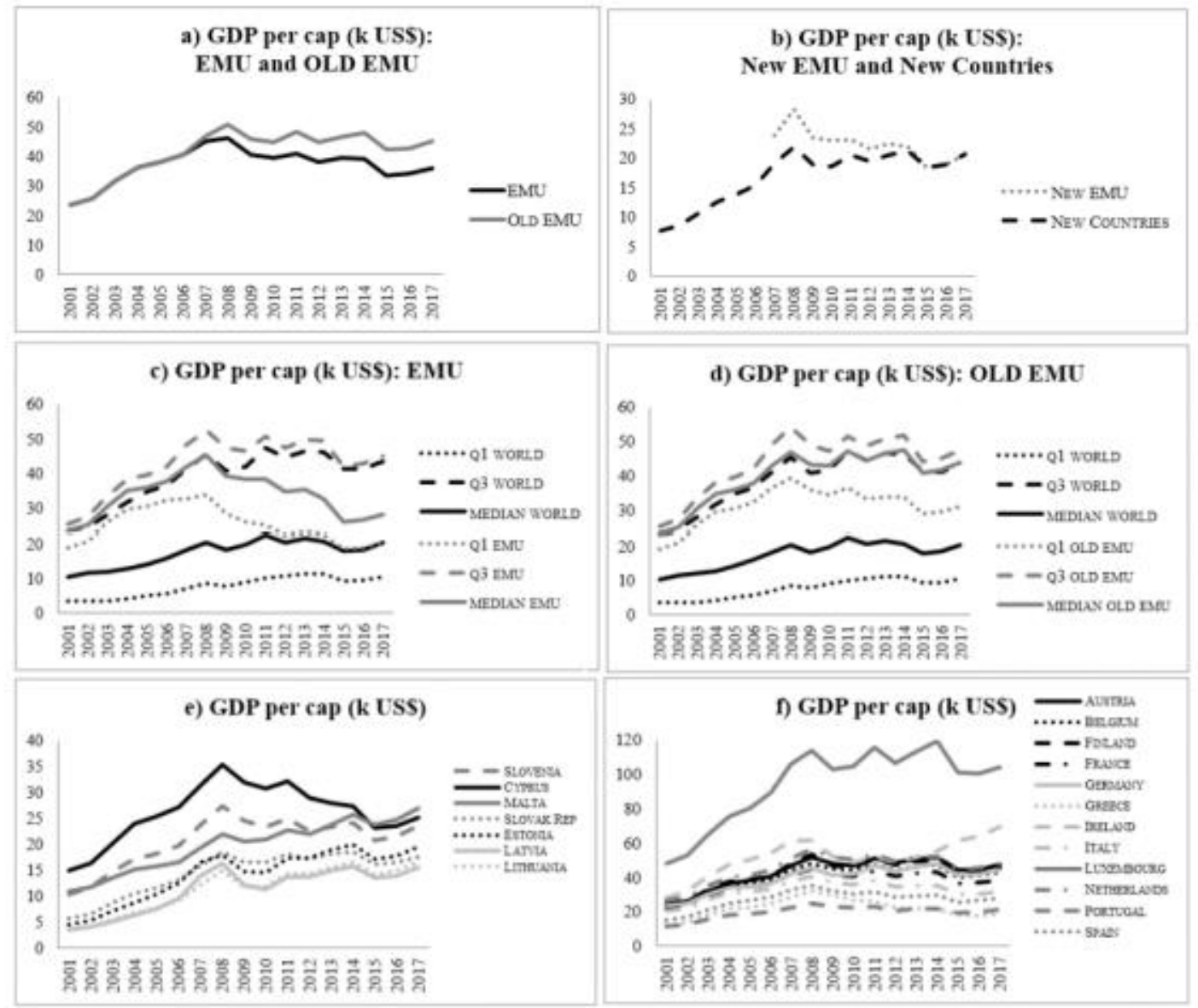

Figure 2. Dynamics of GDP per capita (k US\$).

Note. This table reports the dynamics of the average of the GDP per capita. Panel a) refers to EMU and OLD EMU; panel b) to NEW EMU (dummy equal to 1 when the new country enters the union) and New countries (dummy equal to 1 associated to the new countries, regardless of the time of entry); panel c) reports the first quartile (Q1), the median (MEDIAN) and the third quartile (Q3) for EMU countries, together with the respective world average quartiles; panel d) replicates panel c) for OLD EMU countries (right panel); panel e) reports the dynamics for each of the New countries entering the EMU; panel f) reports the dynamics for each of the OLD EMU countries.

Graphically, we can appreciate the net separation between OLD and NEW EMU, in terms of size of GDP per capita. The EMU countries show a slow decrease in GDP per capita after the crisis due to a combination of a flat trend of OLD EMU and the inclusion of NEW EMU.

Panel c) displays the trend of the median, first and third quartiles of EMU countries' GDP per capita, and the corresponding world quartiles. While the world GDP per capita quartiles are never decreasing after 2007, EMU countries' median and first quartile show a decreasing trend. When comparing this graph with the corresponding OLD EMU's one, in panel d), we can observe that the first quartile still appears slightly decreasing after 2007: even abstracting from the modified composition of the EMU area, the less rich countries among OLD EMU 
seem to have contributed to decrease the average GDP per capita in the EMU area.

To detect any heterogeneity within the group of NEW EMU and within the group of OLD EMU, in panel e) and f), we report, respectively, the dynamics of the GDP per capita of individual member countries.

Since the composition of the NEW EMU group is not fixed, but varies with the entry of new members, the way NEW EMU contribute to the EMU average size can depend both on the entry of new countries and on the change in the average economic size of the NEW EMU countries already in. For instance, an increase in the average size of NEW EMU countries in 2009 can be due either to an increase in the size of Slovenia, Cyprus and Malta (already in), or to the entry of a larger country like Slovakia (just entered), or any combination of the two. Due to the low number of NEW EMU, the dynamics of the average size of the NEW EMU group are quite erratic until 2009, while gets close to the New countries' and the OLD EMU countries' one, thereafter.

We show in panel e) of Figure 2 that the peaks and drops recorded by NEW EMU in 2008 and 2009 are due to the entry of new members. In particular, the entry of Cyprus is responsible of the abrupt increase in the average size of GDP per capita. Finally, panel f) shows some expected differences in GDP per capita levels within the OLD EMU group, but does not reveal any noticeable divergence in trends across countries (Note 17).

\subsection{Institutions}

We now devote our attention to other country characteristics, which might have contributed to the fall in bilateral FPE in the Euro area.

Since fraudulent transactions, bribery, unenforceable contracts, legal and regulation complexity can significantly affect portfolio investment (Gelos \& Wei, 2005; Leuz et al., 2009), an abrupt and unprecedented deterioration of country level governance in EMU countries might have contributed to the collapse of bilateral FPE among EMU countries.

On the one hand, the descriptive statistics in Table 8 reveal that NEW EMU countries feature significantly lower indices of country governance than OLD EMU, so that the enlargement has decreased the average EMU level. On the other hand, the crisis might have deteriorated the country governance standards also in OLD EMU countries, thus making the euro area relatively less attractive.

While the contribution of New countries' country governance to lower the average EMU level is quite mechanical, as shown by the lower institutional indexes in Table 8, the second point deserves a deeper investigation. We argue that one plausible channel through which a crisis may affect country institutions is corruption. The way corruption can lead to a financial crisis is quite intuitive, as exemplified by the outburst of the Greek crisis. However, also the opposite direction of causality is possible: a depressed economic environment can indeed be a fertile ground for corruption and bribery. Melgar et al. (2010), for instance, generally find that better economic results reduce the perception of corruption, while the macroeconomic instability and income inequalities have the opposite effect. Sumah and Mahic (2015), more specifically, find that, during economic crises, a high unemployment and low purchasing power are associated with a rising perception of corruption. Ivlevs and Hinks (2015), by focusing on the change in incidences of bribery in 30 countries in Central Eastern Europe and Central Asia, investigate the micro-mechanisms lying beyond the association, and find that households hit by crisis are more likely to contact and bribe public officials and, therefore, are more likely to engage in corrupt transactions. Gugiu and Gugiu (2016) study instead the association between the economic crisis and corruption in European economies, and find a structural direct positive relationship between the economic crisis and perceptions of corruption. Interestingly, the EU Anti-Corruption Report (European Commission, 2014) highlights that those countries most affected by the economic crisis (e.g., Greece, Italy, Spain, and the Czech Republic), show particularly severe levels of perceived corruption.

Corruption can represent a serious hinder to foreign portfolio investment. If the increase in opacity and transactions costs had been particularly relevant for EMU countries, these factors might have specifically injured the integration in the Euro area.

To test this conjecture, in Table 10, we run a regression, which includes a corruption index as a regressor. We adopt the Difference-in-Difference strategy implemented so far, and include a regressor equal to 1 if the quality of the institutions in the source/host country is "High", that is, above the median ("H_institution"), and 0 otherwise. The (\#a) columns of Table 10 report the interaction of the EMU dummy with the source countries' upper indices, while the (\#b) columns report the interaction with the host countries' ones.

The first index, in columns 1a) and 1b), is "Control of Corruption" drawn from Worldwide Governance Indicators (WGI, Source: World Bank), and captures the perceptions of the extent to which public power is 
exercised for private gain. As an alternative, in columns $2 a$ ) and $2 b$ ), we consider the "Perceived Control of Corruption index" (Source: Transparency International), which captures the perceived level of corruption in the public sector, relying on different country sources. Finally, in columns $3 a$ ) and $3 b$ ), we report the results when considering instead a general measure of country governance, "Rule of Law", also drawn from Worldwide Governance Indicators, and that captures the perceptions of the quality of contract enforcement and property rights (Note 18).

Table 10. FPE and institutional factors

\begin{tabular}{|c|c|c|c|c|c|c|c|c|c|}
\hline & \multicolumn{9}{|c|}{ Dependent variable: $\log (\mathrm{FPE})$} \\
\hline & \multicolumn{5}{|c|}{ Control of Corruption } & \multirow{2}{*}{\multicolumn{4}{|c|}{$\begin{array}{c}\text { Rule of Law } \\
\text { Index WGI (World Bank) }\end{array}$}} \\
\hline & \multicolumn{2}{|c|}{ Index WGI (World Bank) } & \multicolumn{3}{|c|}{ Perceived Index (Transparency Intl.) } & & & & \\
\hline & (1a) & (1b) & (2a) & (2b) & & \multicolumn{2}{|c|}{ (3a) } & \multicolumn{2}{|c|}{ (3b) } \\
\hline \multirow[t]{2}{*}{$\mathrm{EMU}_{\mathrm{s}, \mathrm{h}}$} & $0.413 * * *$ & $0.374 \quad * * *$ & $0.334 \quad * * *$ & 0.264 & ** & 0.619 & **** & 0.520 & **** \\
\hline & $(0.061)$ & $(0.073)$ & $(0.089)$ & $(0.107$ & & $(0.071$ & & $(0.085)$ & \\
\hline \multirow[t]{2}{*}{$\mathrm{H}$ Control of corrupt $\mathrm{WGI}_{\mathrm{s}}$} & 0.029 & 0.068 & & & & & & & \\
\hline & $(0.091)$ & $(0.082)$ & & & & & & & \\
\hline \multirow[t]{2}{*}{$\mathrm{H}$ Control of corrupt $\mathrm{WGI}_{\mathrm{h}}$} & -0.016 & -0.062 & & & & & & & \\
\hline & $(0.050)$ & $(0.062)$ & & & & & & & \\
\hline \multirow[t]{2}{*}{$\mathrm{EMU}_{\mathrm{s}, \mathrm{h}} * \mathrm{H}$ Control of corrupt $\mathrm{WGI}_{\mathrm{s}}$} & $0.166 * *$ & & & & & & & & \\
\hline & $(0.077)$ & & & & & & & & \\
\hline \multirow[t]{2}{*}{$\mathrm{EMU}_{\mathrm{s}, \mathrm{h}} * \mathrm{H}$ Control of corrupt $\mathrm{WGI}_{\mathrm{h}}$} & & $0.225 \quad * * *$ & & & & & & & \\
\hline & & $(0.077)$ & & & & & & & \\
\hline \multirow[t]{2}{*}{$\mathrm{H}$ Perceived control of corrupt $\mathrm{s}_{\mathrm{s}}$} & & & -0.047 & 0.005 & & & & & \\
\hline & & & $(0.144)$ & $(0.130$ & & & & & \\
\hline \multirow[t]{2}{*}{$\mathrm{H}$ Perceived control of corrupt $\mathrm{h}_{\mathrm{h}}$} & & & -0.014 & -0.073 & & & & & \\
\hline & & & $(0.080)$ & $(0.096$ & & & & & \\
\hline \multirow[t]{2}{*}{$\mathrm{EMU}_{\mathrm{s}, \mathrm{h}} * \mathrm{H}$ Perceived control of corrupt $\mathrm{s}_{\mathrm{s}}$} & & & $0.246 \quad * *$ & & & & & & \\
\hline & & & $(0.107)$ & & & & & & \\
\hline \multirow[t]{2}{*}{$\mathrm{EMU}_{\mathrm{s}, \mathrm{h}} * \mathrm{H}$ Perceived control of corrupt $\mathrm{t}_{\mathrm{h}}$} & & & & 0.339 & $* * *$ & & & & \\
\hline & & & & $(0.119$ & & & & & \\
\hline \multirow[t]{2}{*}{$\mathrm{H}$ Rule of law $\mathrm{s}_{\mathrm{s}}$} & & & & & & 0.251 & ** & 0.239 & $* *$ \\
\hline & & & & & & $(0.126$ & & $(0.109)$ & \\
\hline \multirow[t]{2}{*}{ H Rule of lawh } & & & & & & 0.137 & $* * *$ & 0.128 & ** \\
\hline & & & & & & $(0.050$ & & $(0.059)$ & \\
\hline \multirow[t]{2}{*}{$\mathrm{EMU}_{\mathrm{s}, \mathrm{h}} * \mathrm{H}$ Rule of law $\mathrm{s}$} & & & & & & -0.061 & & & \\
\hline & & & & & & $(0.081$ & & & \\
\hline \multirow[t]{2}{*}{$\mathrm{EMU}_{\mathrm{s}, \mathrm{h}} * \mathrm{H}$ Rule of $\operatorname{law}_{\mathrm{h}}$} & & & & & & & & 0.047 & \\
\hline & & & & & & & & $(0.083)$ & \\
\hline \multicolumn{10}{|l|}{$\begin{array}{l}\text { Controls: size, gravity and capital } \\
\text { mobility variables }\end{array}$} \\
\hline Observations & 45216 & 45216 & 45216 & 45216 & & 45216 & & 45216 & \\
\hline Adjusted $R^{2}$ & 0.694 & 0.696 & 0.695 & 0.694 & & 0.696 & & 0.696 & \\
\hline
\end{tabular}

Note. This table reports the results of a Poisson Pseudo Maximum Likelihood regression (Santos Silva and Tenreyro (2006)), as from equation (2) in the main text, with individual country pair fixed-effect and robust standard errors clustered by year. The dependent variable is $\log \left(F P E_{s h}\right)$, where the subscript $s h$ represents the couple investing country $s$-destination country $h$. All controls of Table 2 are included, but not reported. This table considers the interaction of the bilateral EMU dummy $E M U_{s h}$ with two measures of country governance, drawn from the Worldwide Governance Indicators (WGI, World Bank), "Control of Corruption" and "Rule of Law", plus an alternative specification of "perceived control of corruption" (Transparency International) The letter $H$ placed before the institutional variable stands for "High" and indicates a dummy variable equal to 1 if the corresponding institutional variable is above the median, and 0 otherwise. Columns (\#a) consider the size variables relative to the source countries, while columns (\#b) consider the size variables relative to the host countries. ***, **, and * indicate significance at the 1,5 , and $10 \%$ levels, respectively.

The first interesting aspect is that investing or destination countries displaying above the median values of control of corruption, do not display per se larger FPE foreign investments, as proven by the non-statistically significant coefficient of the corresponding variables. Recalling that this coefficient captures the effect for the excluded group, it means that there is no effect for non-EMU countries. Conversely, higher than median Rule of Law, both for source and for host countries, induces larger FPE. 
When looking instead at the interaction of the higher than median control of corruption dummy with the EMU dummy, its coefficient is positive and statistically significant, for both corruption indexes, and regardless of the role of the upper median country (source or host). This result detects a peculiar and exclusive effect played by the control of corruption on EMU country pairs (WGI index: 18\% and 25\% larger bilateral FPE for source and host, respectively; Perceived index: 28\% and 40\% larger bilateral FPE for source and host, respectively). Conversely, no such an additional effect is found for "Rule of law", since all interaction terms' coefficients are non-statistically significant (Note 19).

These findings corroborate the conjecture that the worsening of a specific dimension of institutional standards of EMU destination economies, that is, the control of corruption, likely due to the effect of the crisis, might have triggered a decline in bilateral FPE among EMU countries.

We show the dynamics of these indexes for EMU countries, and then compare them to the world dynamics. We aim at detecting, first, whether the euro area has experienced a relative wider drop in control of corruption, thus becoming particularly less attractive for EMU investors; second, if this worsening of institutional standards is due to the entry of New countries, rather than to a deterioration of old members' country governance after the crisis.

In Figure 3, we show the time-varying average of the two indexes of control of corruption adopted, for the whole EMU group, for OLD EMU, for New countries, and for NEW EMU. We observe that, in general, the indices of New countries and NEW EMU are placed below the indices of OLD EMU. For EMU, we record a downward sloping trend for all indices after the crisis. OLD EMU display a flatter, but still downward sloping dynamic, as well: since the composition of countries within the OLD group is fixed, the decreasing dynamics imply a marginally worsening of the average control of corruption index after the crisis.

The dynamics of EMU reflect the trend of OLD EMU until 2007, and of OLD EMU plus NEW EMU since 2007 onward: since the EMU line is always below the OLD EMU line, it implies that the enlargement to NEW EMU countries has definitely reduced the average level of the control of corruption indexes. However, the way new member countries have contributed to this decrease is less straightforward. The entry of a pool of countries, whose level of the index is lower, inevitably reduces the overall average; but if the distance between EMU and OLD EMU increases over time, then it can be due to a worsening of the indexes of the NEW EMU already in, or to the entry of countries with an equal or even lower institutional level. From panels 1a) and 2a) of Figure 3, we notice that the mean of the indexes for NEW EMU is rather flat since 2009 onwards, and that the mean of New countries across various indices is never decreasing over time: the crisis has not flawed the control of corruption standards of these countries, on average.

Since the composition of the NEW EMU group is not fixed and varies with the entry of new members, the entry of better members in terms of country governance could compensate the behavior of previously entered new members, whose performance could have deteriorated because of the crisis.

To be able to detect this eventual compensation, in panels 1d) and 2d), we show the trend of the two corruption indices for all New countries. We cannot seize any systematic downward trend for any country or any index, as they appear quite flat over time: the erratic dynamics of country governance observed for NEW EMU countries in panel 2a) are rather due to the entry of new members in the group than to the effect of the crisis on incumbent new members.

In panel 1b) and 2b), we compare the dynamics of EMU countries' governance with the world average governance. We observe that the world median, first and third quartile are never decreasing over time, for both indexes of control of corruption. When looking at EMU countries, the third quartile's dynamics are quite flat, while the median, and, more significantly, the first quartile of EMU countries displays an evident downward trend, especially pronounced for the WGI index.

Panel 1c) and 2c) focus on the relative behavior of OLD EMU: the third quartile and the median remain quite flat, but the first quartile, also among OLD EMU countries, shows a downward trend for the WGI index.

This evidence is consistent with our conjecture about the mechanisms behind the collapse of the EMU effect. The bilateral investment within the EMU area are particularly sensitive to "control of corruption", as shown in Table 10. The control of corruption standards of EMU countries have significantly deteriorated relatively to the world standards, because of both the enlargement process, which included countries with weaker institutional standards, and the crisis, which worsened the relative position of the first quartile of OLD EMU. A weaker country governance in the EMU area has induced, in turn, lower investment by all countries, but more than proportionally by other EMU countries, thus contributing to the contraction of the bilateral FPE in the Euro area. 
The decreasing trend in country governance standards of the first quartile of the OLD EMU countries, suggests the presence of significant heterogeneity within the OLD EMU group.

Panels 1e) and 2e) report the dynamics of the control of corruption indexes of the OLD EMU countries: it is immediately evident the decreasing pattern of a group of countries, Greece, Italy, Portugal and Spain, those more severely involved in the sovereign debt crisis (Note 20).

\section{Core vs. Periphery}

Wortmann and Stahl (2016), relying on a broad set of Macroeconomic Imbalance Procedure indicators, detect a homogeneous group of European Union core countries, while countries belonging to the southern periphery, as well as most of the countries of the eastern enlargement, are found to form very distinct clusters in terms of competitiveness, indebtedness, and economic performance.

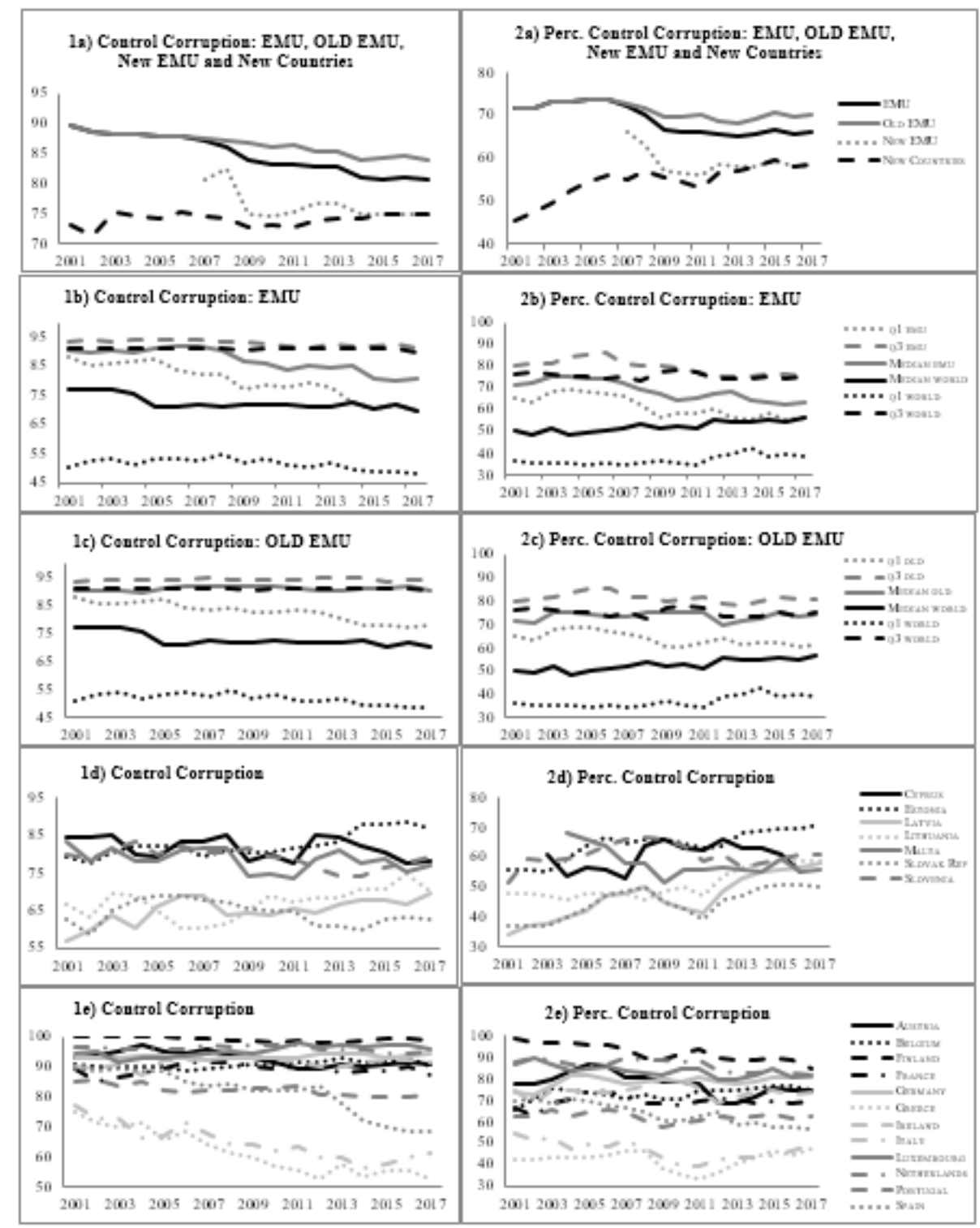

Figure 3. Dynamics of the corruption index.

Note. This table reports the dynamics of the "Control of Corruption" index, drawn from the Worldwide Governance Indicators (WGI, World Bank) in the left panels (column 1), and of the "Perceived Control of Corruption" index, drawn from Transparency International, in the right panels (column 2). Panel a) refers to EMU, OLD EMU, NEW EMU (dummy equal to 1 when the new country enters the union) and New countries (dummy equal to 1 associated to the new countries, regardless of the time of entry); panel b) reports the first quartile (Q1), the median (MEDIAN) and the third quartile (Q3) for EMU countries, together with the respective world average quartiles; panel c) replicates panel b) for OLD EMU countries; panel d) reports the dynamics for each of the new countries entering the EMU; panel e) reports the dynamics for each of the OLD EMU countries. 
Botta et al. (2018) provide empirical evidence about the widening divergence between the macroeconomic performances of core Eurozone countries and peripheral economies.

Lane and Milesi-Ferretti (2017), investigating cross-border holdings of portfolio debt instruments, show how the debt crisis has changed substantially the impact of a common currency on foreign holdings of domestic debt securities, only for countries more directly involved in the sovereign debt crisis.

Panels 1e) and 2e) of Figure 3 suggest that, if the shrinkage in the bilateral FPE in the Euro area is indeed driven by the deterioration of the control of corruption mechanisms, it is likely due to peripheral OLD EMU countries.

Following Lane and Milesi-Ferretti (2017), among others, we distinguish within the OLD EMU group, the "Euro core" countries (Austria, Belgium, Finland, France, Germany, Luxembourg, and the Netherlands) and the "Euro periphery" or "Euro crisis" countries (Greece, Ireland, Italy, Portugal, and Spain), and investigate their investment patterns (Note 21).

Table 11 investigates the patterns of bilateral FPE for core (columns (1a) to (2b)) and periphery Euro countries (columns (3a) to (4b)).

Table 11. Core vs. periphery

\begin{tabular}{|c|c|c|c|c|c|c|c|c|c|c|}
\hline & \multicolumn{10}{|c|}{ Dependent variable: $\log (\mathrm{FPE})$} \\
\hline & \multicolumn{5}{|c|}{ Source Core } & \multicolumn{5}{|c|}{ Source Periphery } \\
\hline & (1a) & (1b) & & (2a) & (2b) & (3a) & (3b) & (4a) & (4b) & \\
\hline Core $_{\mathrm{s}}^{*}$ Core $_{\mathrm{h}}$ & $\begin{array}{l}0.523 * * * \\
(0.011)\end{array}$ & $\begin{array}{r}0.633 \\
(0.036\end{array}$ & 草** & & & & & & & \\
\hline Core $_{\mathrm{s}}{ }^{*}$ Core $_{\mathrm{h}}{ }^{*}$ Crises & & $\begin{array}{l}-0.188 \\
(0.032\end{array}$ & $\begin{array}{l}* * * \\
)^{*}\end{array}$ & & & & & & & \\
\hline Core $_{\mathrm{s}}{ }^{*}$ Core $_{\mathrm{h}}{ }^{*}$ Post crises & & $\begin{array}{r}-0.133 \\
(0.051\end{array}$ & $\begin{array}{l}* * * \\
\text { ) }\end{array}$ & & & & & & & \\
\hline Cores $^{*}{ }^{*}$ Periphery $_{h}$ & & & & $\begin{array}{l}0.251 \text { *** } \\
(0.011)\end{array}$ & $\begin{array}{l}0.625 \text { *** } \\
(0.039)\end{array}$ & & & & & \\
\hline Core $_{\mathrm{s}}$ Periphery $_{\mathrm{h}} *$ Crises & & & & & $\begin{array}{l}-0.575 \text { *** } \\
(0.079)\end{array}$ & & & & & \\
\hline Core $_{s}{ }^{*}$ Periphery ${ }_{\mathrm{h}}$ *Post crises & & & & & $\begin{array}{l}-0.580 \text { *** } \\
(0.056)\end{array}$ & & & & & \\
\hline Periphery ${ }_{\mathrm{s}}{ }^{\mathrm{Core}_{\mathrm{h}}}$ & & & & & & $\begin{array}{l}0.443 \text { *** } \\
(0.034)\end{array}$ & $\begin{array}{l}0.418{ }^{* * *} \\
(0.029)\end{array}$ & & & \\
\hline Periphery ${ }_{\mathrm{s}}{ }^{*}$ Core $_{\mathrm{h}}{ }^{*}$ Crises & & & & & & & $\begin{array}{l}-0.129 \text { *** } \\
(0.037)\end{array}$ & & & \\
\hline Periphery $_{\mathrm{s}}{ }^{*} \mathrm{Core}_{\mathrm{h}} *$ Post crises & & & & & & & $\begin{array}{l}0.147 \text { *** } \\
(0.047)^{2}\end{array}$ & & & \\
\hline Periphery ${ }^{*}{ }^{*}$ Periphery $y_{h}$ & & & & & & & & $\begin{array}{l}0.745 * * * \\
(0.011)\end{array}$ & $\begin{array}{l}0.733 * \\
(0.113)\end{array}$ & **** \\
\hline Periphery $_{\mathrm{s}}{ }^{*}$ Periphery $_{\mathrm{h}}{ }^{*}$ Crises & & & & & & & & & $\begin{array}{l}0.300 * \\
(0.152)\end{array}$ & *** \\
\hline Periphery ${ }_{\mathrm{s}}{ }^{*}$ Periphery ${ }_{\mathrm{h}}{ }^{*}$ Post crises & & & & & & & & & $\begin{array}{c}-0.257 \text { * } \\
(0.114)\end{array}$ & ** \\
\hline Crises & $\begin{array}{c}-0.130 \\
(0.109)\end{array}$ & $\begin{array}{c}-0.119 \\
(0.110\end{array}$ & & $\begin{array}{c}-0.136 \\
(0.109)\end{array}$ & $\begin{array}{c}-0.123 \\
(0.109)\end{array}$ & $\begin{array}{c}-0.139 \\
(0.108)\end{array}$ & $\begin{array}{c}-0.138 \\
(0.108)\end{array}$ & $\begin{array}{c}-0.138 \\
(0.109)\end{array}$ & $\begin{array}{l}-0.140 \\
(0.109)\end{array}$ & \\
\hline Post crises & $\begin{array}{l}0.270 * * * \\
(0.086)\end{array}$ & $\begin{array}{r}0.278 \\
(0.086\end{array}$ & $\begin{array}{l}* * * * \\
)\end{array}$ & $\begin{array}{l}0.265 \text { *** } \\
(0.085)\end{array}$ & $\begin{array}{l}0.277 \text { *** } \\
(0.086)\end{array}$ & $\begin{array}{l}0.260 * * * \\
(0.084)\end{array}$ & $\begin{array}{l}0.258 * * * \\
(0.084)\end{array}$ & $\begin{array}{l}0.262 \text { *** } \\
(0.085)\end{array}$ & $\begin{array}{l}0.263 \text { * } \\
(0.085)\end{array}$ & **** \\
\hline $\begin{array}{l}\text { Size, gravity and capital mobility } \\
\text { variables included }\end{array}$ & & & & & & & & & & \\
\hline Observations & 45216 & 45216 & & 45216 & 45216 & 45216 & 45216 & 45216 & 45216 & \\
\hline Adjusted $R^{2}$ & 0.717 & 0.717 & & 0.709 & 0.709 & 0.710 & 0.710 & 0.709 & 0.709 & \\
\hline
\end{tabular}

Note. This table reports the results of a Poisson Pseudo Maximum Likelihood regression (Santos Silva and Tenreyro (2006)), as from equation (2) in the main text, with individual country pair fixed-effects and robust standard errors clustered by year. The dependent variable is $\log \left(F P E_{s h}\right)$, where the subscript $s h$ represents the couple investing country $s$-destination country $h$. All controls of Table 2 are included, but not reported. In this table, the group of OLD EMU countries is split into core and periphery countries. The columns (\#a) and (\#b) consider specifications, respectively, without and with interactions with crisis and post-crisis dummy. The columns (1a) to (2b) consider the Core countries investing in Core $_{h}$ countries or in Periphery $y_{h}$ countries, while columns (3a) to (4b) consider the Periphery ${ }_{s}$ countries investing in $\mathrm{Core}_{h}$ countries or in Periphery $\mathrm{h}_{h}$ countries. ***,**, and * indicate significance at the 1,5, and $10 \%$ levels, respectively. 
In column (1a) and (1b) of Table 11, we observe that bilateral FPE among Euro core countries suffered for the crisis, but not dramatically (from $88 \%$ larger investment before the crisis, to $56 \%$ during the crisis, to $65 \%$ after the crisis). When considering, instead, the cross investment of Euro core countries in Euro periphery countries (columns (2a) and (2b)), we observe a clear picture of the collapse of the EMU linkages: on the whole period, their investments are $29 \%$ larger than other countries, starting from $87 \%$ larger in the pre-crisis period, to only $5 \%$ larger investment after the crisis.

When considering the investments of Euro periphery source countries in Euro core countries, in columns (3a) and (3b) of Table 11, we observe that they are on average 56\% larger than other country pairs, starting from 52\% in the pre-crisis period, to $34 \%$ during the crisis and increasing up to $76 \%$ after the crisis.

Finally, the last two columns of Table 11 report the results relative to the within Euro periphery group: the average investments are 110\% larger than other country pairs; starting from 108\% larger FPE before the crisis, up to $181 \%$ during the crisis, but dropping to a $61 \%$ higher FPE after the crisis: the drop of bilateral investment among periphery economies seems to have occurred majorly after the crisis.

Table 12. New countries and Core/periphery

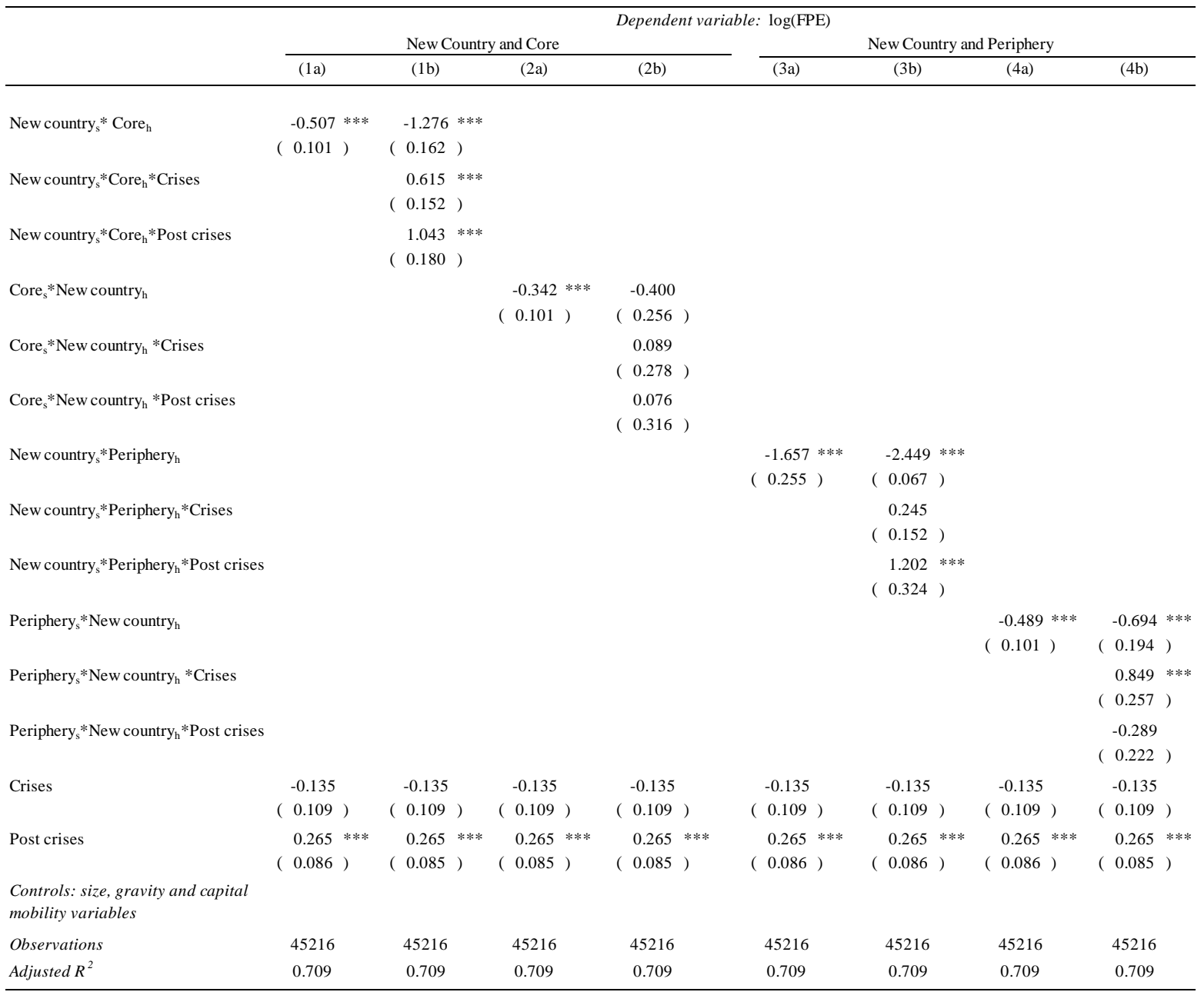

Note. This table reports the results of a Poisson Pseudo Maximum Likelihood regression (Santos Silva and Tenreyro (2006)), as from equation (2) in the main text, with individual country pair fixed-effects and robust standard errors clustered by year. The dependent variable is $\log \left(F P E_{\text {sh }}\right)$, where the subscript $s h$ represents the couple investing country $s$-destination country $h$. All controls of Table 2 are included, but not reported. The columns (\#a) and (\#b) consider specifications, respectively, without and with interactions with crisis and post-crisis dummy. The columns (1a) to (2b) consider the investment patterns between Core and New Countries, while columns (3a) to (4b) consider the investment patterns between Periphery and New countries. ***, **, and * indicate significance at the 1,5 , and $10 \%$ levels, respectively. 
The findings of Table 11 suggest the hypothesis of a crucial role played by Euro periphery countries as destination economies. The core-periphery linkages are the ones that have experienced the harshest deterioration after the crisis.

This outcome is consistent with the above mentioned conjecture: when the peripheral countries standards of living (GDP per capita), but, more markedly, control of corruption started deteriorating, core countries first, and, other periphery countries at a later stage, started withdrawing their foreign investment there, thus accelerating the fall of FPE in the EMU area.

To conclude the overview of the integration process in the Euro area, we report in Table 12, the evolution of the investment patterns between New countries and OLD EMU, split in core and periphery countries (Note 22).

To investigate the evolution over time of the linkages between New members and Euro core/periphery members, we refer to the investment behavior of New countries, before and after the crisis.

In Table 12, we observe that New countries, in the whole period, invest in core countries $40 \%$ less than other country pairs (column (1a)), but we observe in column (1b) that this average is the outcome of a quite negative starting point before the crisis (-72\%), an improvement during the crisis $(-45 \%)$, and a further rising after the crisis $(-21 \%)$.

When looking instead at the inward investment in New countries by Euro core economies (columns (2a) and (2b)), we observe that the average underweighting is equal to $-29 \%$, with no significant effect over time. New countries underweight Euro periphery economies more than Euro core periphery: the average - $81 \%$ (column (3a)) reflects a $-91 \%$ before and during the crisis and a marginal improvement to $-71 \%$ after the crisis (column (3b)). Euro periphery countries invest in New countries $39 \%$ less than other country pairs, starting from an initial $-50 \%$ (column (4a)), increasing their investment during the crisis, even overcompensating the initial undervaluation $(+17 \%)$, but then stepping back to the pre-crisis investment level (column (4b)).

The dynamics of the investment patterns between New countries, core and periphery OLD EMU can be summarized as follows. First, periphery and core countries generally underweight New countries' equities in their portfolios, thus not contributing to tighten the EMU linkages that the crisis has loosened. Second, New countries underweight peripheral countries more heavily than core countries, in line with the institutional interpretation proposed so far. Finally, New countries, though generally underweighting OLD EMU countries in their portfolios, show a significant rise in their investments in both peripheral and core countries over time, that is consistent with their progressive integration after the enlargement as investing though not as recipient economies.

\section{Conclusions}

Two decades after the inception of the Euro, the common currency effect on bilateral foreign portfolio equities has decreased by $40 \%$. This paper tries to describe, measure, and interpret this finding. We disentangle the investment dynamics of old members, to distinguish the role of the crisis from that of the enlargement: since also the drop among the original EMU members is very close to $40 \%$, the crisis appears to have played a major role over the enlargement process.

We test the conjecture that the shrinkage of the EMU effect is attributable to a decline in economic development and country governance standards. The empirical evidence does not reject this hypothesis. On the one hand, the crisis has deteriorated the wealth and the institutional standards of old member countries. On the other hand, the enlargement has opened the union to countries with lower economic development and country governance, thus making these economies not attractive enough for old members.

Among OLD EMU countries, we detect a peculiar deterioration of the control of corruption standards of Euro periphery countries, those more severely injured by the sovereign debt crisis. The financial linkages between periphery and core countries, quite strong before the crisis, experienced a collapse afterwards, thus dragging down the linkages in the OLD EMU group.

It is worth stressing that this paper does not aim to assess and measure the benefits of enlargement, which cannot be constrained to the narrow perspective of financial integration in foreign portfolio equities. The enlargement process has proven so far quite weak in fostering investment from old to new members, but has significantly increased the holdings of new countries in old members' markets. This paper suggests instead that, one the one hand, the improvement of country governance in old members' economies severely hit by the crisis, and, on the other hand, a convergence of new members' institutional standards to the old members' ones are valuable means to restore and further tighten stock market integration in the enlarged euro area in the near future. 


\section{Acknowledgments}

We are grateful to Youssef Ghallada, Christian Friedrich and to participants in the 2020 European Economic Association Virtual Congress (Rotterdam), CEREC Finance Conference (Bruxelles) and 23rd FMM Conference (Berlin) for very helpful comments. The usual disclaimer applies.

\section{References}

Allen, F., \& Song, W. (2005). Financial integration and EMU. European Financial Management, 11(1), 7-24. https://doi.org/10.1111/j.1354-7798.2005.00273.x

Balta, N., \& Delgado, J. (2009). Home bias and market integration in the EU. CESifo Economic Studies, 55, 110-144. https://doi.org/10.1093/cesifo/ifn037

Baltzer, M., Cappiello, L., Santis, R. D., \& Manganelli, S. (2008). Measuring financial integration in new EU member states. European Central Bank Occasional Paper Series, 81, March. https://doi.org/10.2139/ssrn.1084908

Berkel, B. (2004). Institutional determinants of international equity portfolios- a country-level analysis. EFA 2004 Maastricht Meetings Paper No. 2899. https://doi.org/10.2139/ssrn.576881

Botta, A., Tippet, B., \& Onaran, O. (2018). Divergence between the core and the periphery and secular stagnation in the Eurozone. Greenwich Papers in Political Economy 20405.

Brière, M., Chapelle, A., \& Szafarz, A. (2012). No contagion, only globalization and flight to quality. Journal of International Money and Finance 31, 1729-1744. https://doi.org/10.1016/j.jimonfin.2012.03.010

Broner, F., Didier, T., Erce, A., \& Schmukler, S. L. (2013). Gross capital flows: Dynamics and crises. Journal of Monetary Economics, 60, 113-133. https://doi.org/10.1016/j.jmoneco.2012.12.004

Chan, K., Covrig, V., \& Ng, L. (2005). What determines the domestic bias and foreign bias? Evidence from mutual fund equity allocations worldwide. Journal of Finance, 60, 1495-1534. https://doi.org/10.1111/j.1540-6261.2005.768_1.x

Damgaard, J., Elkjaer, T., \& Johannesen, N. (2018). Piercing the veil. International Monetary Fund: Finance and Development Quarterly, 55(2), 50-53.

De Grauwe, P., \& Ji, Y. (2018). Core-periphery relations in the eurozone. The Economists Voice, 15(1), 1-15. https://doi.org/10.1515/ev-2018-0027

Dunis, C., Sermpinis, G., \& Karampelia, M. (2013). Stock market linkages among new EMU members and the euro area: Implications for financial integration and portfolio diversification. Studies in Economics and Finance, 30(4), 370-388. https://doi.org/10.1108/SEF-04-2012-0048

European Commission. (2014). EU anti-corruption report. Brussels: European Commission.

Fidora, M., Fratzscher, M., \& Thimann, C. (2007). Home bias in global bond and equity markets: The role of real exchange rate volatility. Journal of International Money and Finance, 26, 631-655. https://doi.org/10.1016/j.jimonfin.2007.03.002

Gelos, R., \& Wei, S. (2005). Transparency and international portfolio holdings. Journal of Finance, 60, 2987-3020. https://doi.org/10.1111/j.1540-6261.2005.00823.x

Giannetti, M., \& Koskinen, Y. (2010). Investor protection, equity returns and financial globalization. Journal of Financial and Quantitative Analysis, 45, 135-168. https://doi.org/10.1017/S0022109009990524

Giofré, M. (2012). Convergence of EMU equity portfolios. Open Economies Review, 23(2), 381-19. https://doi.org/10.1007/s11079-011-9197-1

Giofré, M. (2013). Investor protection rights and foreign investment. Journal of Comparative Economics, 41, 506-526. https://doi.org/10.1016/j.jce.2012.07.002

Goldberger, A. (1968). The interpretation and estimation of Cobb-Douglas functions. Econometrica, 36, 464-472. https://doi.org/10.2307/1909517

Gugiu, M., \& Gugiu, P. (2016). Economic crisis and corruption in the European Union. Journal of Methods and Measurement in the Social Sciences, 7(1), 1-22. https://doi.org/10.2458/v7i1.19398

Harkmann, K. (2020). Integration of the Baltic stock markets with developed European markets. International Journal of Finance and Economics. https://doi.org/10.1002/ijfe.2165

Hartmann, P., Straetmans, S., \& de Vries, C. (2004). Asset market linkages in crisis periods. Review of 
Economics and Statistics, 86(1), 313-326. https://doi.org/10.1162/003465304323023831

Ivlevs, A., \& Hinks, T. (2015). Global economic crisis and corruption. Public Choice. 162, 425-445. https://doi.org/10.1007/s11127-014-0213-Z

Lane, P. (2006). Global bond portfolios and EMU. International Journal of Central Banking. 2, 1-3. https://doi.org/10.2139/ssrn.925858

Lane, P. (2008). EMU and financial integration. IIIS Discussion Paper 272.

Lane, P. (2013). Capital flows in the euro area. European Commission, Economic Papers 497. https://doi.org/10.1057/9781137361943_20

Lane, P., \& Milesi-Ferretti, G. (2007). The international equity holdings of euro area investors. In R. Anderton, \& F. di Mauro (Eds.), The Importance of the External Dimension for the Euro Area: Trade, Capital Flows, and International Macroeconomic Linkages. Cambridge University Press.

Lane, P., \& Milesi-Ferretti, G. (2017). International financial integration in the aftermath of the global financial crisis. IMF Working Papers 17/115. https://doi.org/10.5089/9781484300336.001

Leuz, C., Lins, K., \& Warnock, F. (2009). Do foreigners invest less in poorly governed firms? Review of Financial Studies, 22, 3245-3285. https://doi.org/10.1093/rfs/hhn089

Linnemann, H. (1966). An econometric study of international trade flows. Amsterdam: North-Holland Publishing Co.

Longstaff, F. (2010). The subprime credit crisis and contagion in financial markets. Journal of Financial Economics, 97, 436-450. https://doi.org/10.1016/j.jfineco.2010.01.002

Manning, W., \& Mullahy, J. (2001). Estimating log models: To transform or not to transform? Journal of Health Economics, 20, 461-494. https://doi.org/10.1016/s0167-6296(01)00086-8

Masten, A., Coricelli, F., \& Masten, I. (2008). Non-linear growth effects of financial development: Does financial integration matter? Journal of International Money and Finance, 27(2), 295-313. https://doi.org/10.1016/j.jimonfin.2007.12.009

Melgar, N., Rossi, M., \& Smith, T. (2010). The perception of corruption. International Journal of Public Opinion Research, 22(1), 120-131. https://doi.org/10.1093/ijpor/edp058

Milesi-Ferretti, G., \& Tille, C. (2011). The great retrenchment: International capital flows during the global financial crisis. Economic Policy, 26, 289-346. https://doi.org/10.1111/j.1468-0327.2011.00263.x

Portes, R., \& Rey, H. (2005). The determinants of cross-border equity flows. Journal of International Economics, 65, 269-296. https://doi.org/10.1016/j.jinteco.2004.05.002

Portes, R., Rey, H., \& Oh, Y. (2001). Information and capital flows: The determinants of transactions in financial assets. European Economic Review, 45, 783-796. https://doi.org/10.1016/S0014-2921(01)00138-6

Santos, S. J., \& Tenreyro, S. (2006). The log of gravity. The Review of Economics and Statistics, 88(4), 641-58. https://doi.org/10.1162/rest.88.4.641

Slavov, S. (2009). Do common currencies facilitate the net flow of capital among countries? The North American Journal of Economics and Finance, 20(2), 124-144. https://doi.org/10.1016/j.najef.2009.03.003

Sorensen, B. E., Wu, Y., Yosha, O., \& Zhu, Y. (2007). Home bias and international risk sharing: Twin puzzles separated at birth. Journal of International Money and Finance, 26, 587-605. https://doi.org/10.1016/j.jimonfin.2007.03.005

Sousa, J. D., \& Lochard, J. (2011). Does the single currency affect foreign direct investment? The Scandinavian Journal of Economics, 113(3), 553-578. https://doi.org/10.1111/j.1467-9442.2011.01656.x

Sumah, S., \& Mahic, E. (2015). Impact on the perception of corruption. IOSR Journal of Humanities and Social Science, 20(11), 21-29.

Tinbergen, J. (1962). Shaping the world economy. New York: Twentieth Century Fund.

Vermeulen, R. (2013). International diversification during the financial crisis: A blessing for equity investors? Journal of International Money and Finance, 35, 104-123. https://doi.org/10.1016/j.jimonfin.2013.01.003

Wortmann, M., \& Stahl, M. (2016). One size fits some: A reassessment of EMU's core -periphery framework. Journal of Economic Integration, 31(2), 377-413. https://doi.org/10.11130/jei.2016.31.2.377 
Zoromé, A. (2007). Concept of offshore financial centers: In search of an operational definition. IMF Working Paper WP/07/87. https://doi.org/10.5089/9781451866513.001

\section{Notes}

Note 1. Our data are time varying, but for the sake of simplicity in notation, we drop the time index in the equations.

Note 2. Note that if the coefficient is null (or non-statistically significant) then $\mathrm{e}^{0}-1=0$, i.e., the dummy has no significant effect on the dependent variable.

Note 3. The subscript "*" indicates $s h, s$ or $h$, when the EMU dummy is, respectively, bilateral, source country-specific or host country-specific.

Note 4. Since the seminal works of Tinbergen (1962) and Linnemann (1966), the gravity models, originally formulated in multiplicative form, have been extensively applied using the log-linearized form to estimate the parameter of factors predicting regional patterns of trade, foreign direct investment, and, more recently, foreign portfolio investment. Although the problem of obtaining consistent estimates of the conditional mean of the dependent variable, when the model is estimated in the log linear form, was already known (Goldberger, 1968; Manning \& Mullahy, 2001), the gravity literature seems to have neglected the issue until the work by Santos Silva and Tenreyro (2006). As a solution, these authors proposed the Poisson pseudo-maximum likelihood estimator, which is consistent in the presence of heteroskedasticity, and also provides a natural way to deal with zero values of the dependent variable.

Note 5. See Appendix A for the full list of investing and destination countries.

Note 6. See data.imf.org/cpis, for more details on the survey.

Note 7. In Table 4 (and 4A in Appendix B), we also consider alternative stricter classifications, which exclude a larger number of destination economies as offshore centers.

Note 8. As reported by the IMF, in some cases within the CPIS, negative values are reported for the value of residents' holdings of securities issued by a particular economy. Such entries reflect short positions in securities, usually resulting from the sale of securities acquired under repurchase agreements. In our sample, the number of negative positions is very low (74 out of about 50 thousands of observations) and so is their absolute value, therefore, we exclude them from the sample.

Note 9. These indexes are described in Section 6.2 and in Appendix A.

Note 10. Differently from standard gravity models in the trade literature, we include also country-pair fixed effects, in order to properly isolate the EMU effect on FPE. Since, for instance, the Australia-Argentina effect is fixed over time, but differs from the Argentina-Australia effect, the coefficient of the distance variable (equal for country pairs, regardless of which is the investing or destination economy) can be estimated. The relative small size of the coefficient of the distance is then due to the fact that it captures its effect on FPE, after partialling out country-pair fixed effect.

Note 11. Actually, Slovenia is always present in the CPIS dataset as destination economy, but as investing country only since 2008 onwards.

Note 12. In Table 4A, in Appendix B, columns (1) to (4) follow an alternative classification (Lane \& Milesi-Ferretti, 2017): beyond the offshore countries considered in the baseline specification, also Belgium, Cyprus and Malta, among EMU countries, are included in the list. For a detailed list of offshore centers in the different specifications, see Appendix A.

Note 13. A coefficient of $E M U_{s h}$ equal to 0 (non-statistically significant), would imply an effect on bilateral FPE equal to $\left(\mathrm{e}^{0}-1\right) \cdot 100=0$ : EMU members invest each other exactly like other countries, meaning no EMU effect. Negative coefficients would imply instead that EMU countries reciprocally invest less than other country-pairs.

Note 14. We consider the dichotomic version of size and institutional variables, just to facilitate the interpretation of the coefficient of the interaction terms with the EMU dummy variables. Results on the continuous versions of the size and institutional covariates are fully in line with the binary ones (and available upon request from the authors).

Note 15. Figure 2A in Appendix B reports the same dynamics of Figure 2, but relative to GDP in US\$. The dynamics of stock market capitalization are not reported, because the regressor, to avoid endogeneity, is included in the analysis at its beginning of period level. 
Note 16. Due to scaling problems, we show different figures to appreciate the dynamics of New EMU and New countries, on the one hand, and of OLD members, on the other hand. We recall that the mean of the NEW EMU and New countries are different: the former represents the mean of the countries joining the union, as far as they enter (e.g., Lithuania contributes to the mean only since 2015 onwards), while the latter represents the mean of all New countries that joined the union after the enlargement, regardless of their time of entry (e.g., Lithuania contributes to the mean since 2001).

Note 17. It is worth underlining that, to check for scaling problems, we have also split the OLD EMU sample in large and small countries, but we could not detect any peculiarity in the dynamics of OLD EMU.

Note 18. In Table 10A in Appendix B, we consider, as a country governance index alternative to "Rule of Law", "Government effectiveness" (capturing the perceptions of government credibility and independence of public services from political pressures) and "Regulation quality" (capturing perceptions of the ability of the government to promote private sector development), with results similar to "Rule of Law".

Note 19. In Table 10A, when considering "Government Effectiveness" and "Regulation" as an alternative country governance to "Rule of Law", we find similar findings: significant impact per se, but not additional contribution for EMU country pairs (with the only exception of a 10\% significant coefficient in column 1a)).

Note 20. Figure 3A in Appendix B, shows the same dynamics for the other three general country governance indexes (Rule of Law, Government Effectiveness, and Regulation). The dynamics are close to the ones found for the control of corruption index.

Note 21. Note that this classification is adopted, among others, also by De Grauwe and Ji (2018), who argue that there is no deterministic force that condemns countries in the periphery to stay in the periphery indefinitely, and that countries that are in the periphery today can become part of the core, and vice versa.

Note 22. Table 12A reports the same analysis, but considering the interaction of NEW EMU, rather than the New countries, with core and periphery OLD EMU countries.

\section{Appendix A. Data}

\section{Dependent variable}

Foreign Portfolio Equities: Cross-border holdings of equities issued by host country residents and hold by the source country residents. Source: Coordinated Portfolio Investment Survey (IMF).

Investing and destination countries

Argentina, Australia, Austria, Bahrain, Barbados, Belgium, Brazil, Bulgaria, Canada, Chile, China Hong Kong, China, Colombia, Costa Rica, Cyprus, Czech Republic, Denmark, Egypt, Estonia, Finland, France, Germany, Greece, Hungary, Iceland, India, Indonesia, Ireland, Israel, Italy, Japan, Kazakhstan, Korea, Kuwait, Latvia, Lebanon, Lithuania, Luxembourg, Malaysia, Malta, Mauritius, Mexico, Mongolia, Netherlands, New Zealand, Norway, Pakistan, Panama, Philippines, Poland, Portugal, Romania, Russia, Saudi Arabia, Singapore, Slovak Republic, Slovenia, South Africa, Spain, Sweden, Switzerland, Thailand, Turkey, Ukraine, United Kingdom, United States, Uruguay, Venezuela.

Offshore centres

Note that, as exception to the list above, the below mentioned countries are considered as investing, but not as destination economies.

Baseline specification: the Netherlands, Luxembourg, Hong Kong SAR, Ireland, and Singapore (Damgaard et al., 2018).

Robustness, Table 4 (5)-(8): Bahrain, Barbados, Hong Kong, Cyprus, Ireland, Luxembourg, Malta, Mauritius, Panama, Singapore, Switzerland, United Kingdom, Latvia, Uruguay (Zoromé, 2007).

Robustness, Table 4A (1)-(4): Bahrain, Hong Kong, Cyprus, Ireland, Luxembourg, Malta, Mauritius, the Netherlands, Panama, Singapore, Switzerland, Belgium, United Kingdom (Lane \& Milesi-Ferretti, 2017)

\section{Size variables}

Market capitalization: Market value for listed domestic companies (in current U.S.\$, year 2001). Source: Federal Reserve Economic Data (FRED).

GDP per capita: Gross domestic product divided by midyear population (in current U.S.\$).

Source: World Development Indicators, World Bank. 
GDP in US\$: Gross Domestic Product, Current U.S. Dollars, annual, Not Seasonally Adjusted. Federal Reserve Economic Data (FRED).

\section{Gravity variables}

Distance: Measure of the distance between the capital of the source and the host country, estimated with the great circle distance in miles. Source: CEPII's distance measures, the GeoDist database. Border dummy: Dummy variable that takes the value equal to 1 when a pair of countries have at least one border in common, and 0 otherwise. Source: CEPII's distance measures, the GeoDist database.

Colonial dummy: Dummy variable that takes the value equal to 1 for those pair of countries that share a common colonial past, and 0 otherwise. Source: CEPII's distance measures, the GeoDist database.

Language dummy: Dummy variable that takes the value equal to 1 when a pair of countries have an official language in common, and 0 otherwise. Source: CEPII's distance measures, the GeoDist database.

Legal origins dummy: Dummy variable that takes the value equal to 1 for those pair of countries that share a common origin (British, French, Socialist, German or Scandinavian).

\section{Capital mobility}

Capital mobility: Rank from 1 to 10 of the capital mobility, for both the source and the host country.

Source: Economic Freedom of the World.

\section{Institutional variables}

Perceived Corruption Index. The index scores and ranks countries and territories around the world on the perceived level of corruption in the public sector. It is an aggregate index, which scores 1-100, from very clean to highly corrupted countries, and which draws on a number of different data sources that capture business and expert views across different countries.

Source: Transparency International (https://www.transparency.org/en/cpi).

Control of Corruption: Percentile Rank of control of corruption in the host country. Control of corruption captures perceptions of the extent to which public power is exercised for private gain, including both petty and grand forms of corruption, as well as "capture" of the state by elites and private interests. Source: Worldwide Governance Indicators.

Rule of Law: Percentile Rank of rule of law in the host country. Rule of law captures perceptions of the extent to which agents have confidence in and abide by the rules of society, and in particular the quality of contract enforcement, property rights, the police, and the courts, as well as the likelihood of crime and violence. Source: Worldwide Governance Indicators.

Government effectiveness: Percentile Rank of government effectiveness in the host country. Government effectiveness captures perceptions of the quality of public services, the quality of the civil service and the degree of its independence from political pressures, the quality of policy formulation and implementation, and the credibility of the government's commitment to such policies.

Source: Worldwide Governance Indicators.

Regulatory quality: Percentile Rank of regulatory quality in the host country. Regulatory quality captures perceptions of the ability of the government to formulate and implement sound policies and regulations that permit and promote private sector development.

Source: Worldwide Governance Indicators.

\section{EMU dummies}

$\underline{E M U_{s h}}$ : Dummy variable that takes the value equal to 1 for each pair of countries that are both members of EMU, and 0 otherwise.

$\underline{E M U_{S}}$ : Dummy variable that takes the value equal to 1 for investing countries that are EMU members, and 0 otherwise $\left(E M U_{h}: 1\right.$ for host countries that are EMU members, and 0 otherwise). $\underline{O L D E M U_{S}}$ : Dummy variable that takes the value equal to 1 for investing countries that are original EMU members, and 0 otherwise ( $\underline{O L D}$ $\underline{E M U_{h}}: 1$ for host countries that are original EMU members, and 0 otherwise).

New country: Dummy variable that takes the value equal to 1 for those investing countries, which entered the EMU after the enlargement, and 0 otherwise, independently of the year in which they joined the EMU (New country $_{h}: 1$ for host countries that enter the EMU after the enlargement, and 0 otherwise). 
Cores $_{s}$ : Dummy variable that takes the value equal to 1 if the investing countries are the core-EMU, that is, Austria, Belgium, Finland, France, Germany, Luxembourg, and the Netherlands, and 0 otherwise ( Core $_{h}: 1$ if the host countries are the core-EMU, and 0 otherwise).

Periphery $_{\Sigma^{\prime}}$ : Dummy variable that takes the value equal to 1 if the investing countries are the periphery-EMU, that is, Greece, Ireland, Italy, Portugal, and Spain, and 0 otherwise (Periphery $\underline{h}: 1$ if the host countries are the periphery-EMU, and 0 otherwise).

\section{Crises dummies}

Financial crisis: Dummy variable taking the value equal to 1 for 2008-2009 years, and 0 otherwise. Post financial crisis: Dummy variable taking the value 1 for 2010-2017 years, and 0 otherwise. Crises: Dummy variable that captures both the financial and the sovereign debt crisis; it takes the value equal to 1 for 2008-2012 years, and 0 otherwise (in the specification of Table 4A, columns (5) to (8), the crisis period starts in 2007).

Post crises: Dummy variable taking the value 1 for 2013-2017 years, and 0 otherwise.

\section{Appendix B. Additional Tables}

Table 4A. Robustness: alternative offshore sample and crisis definition

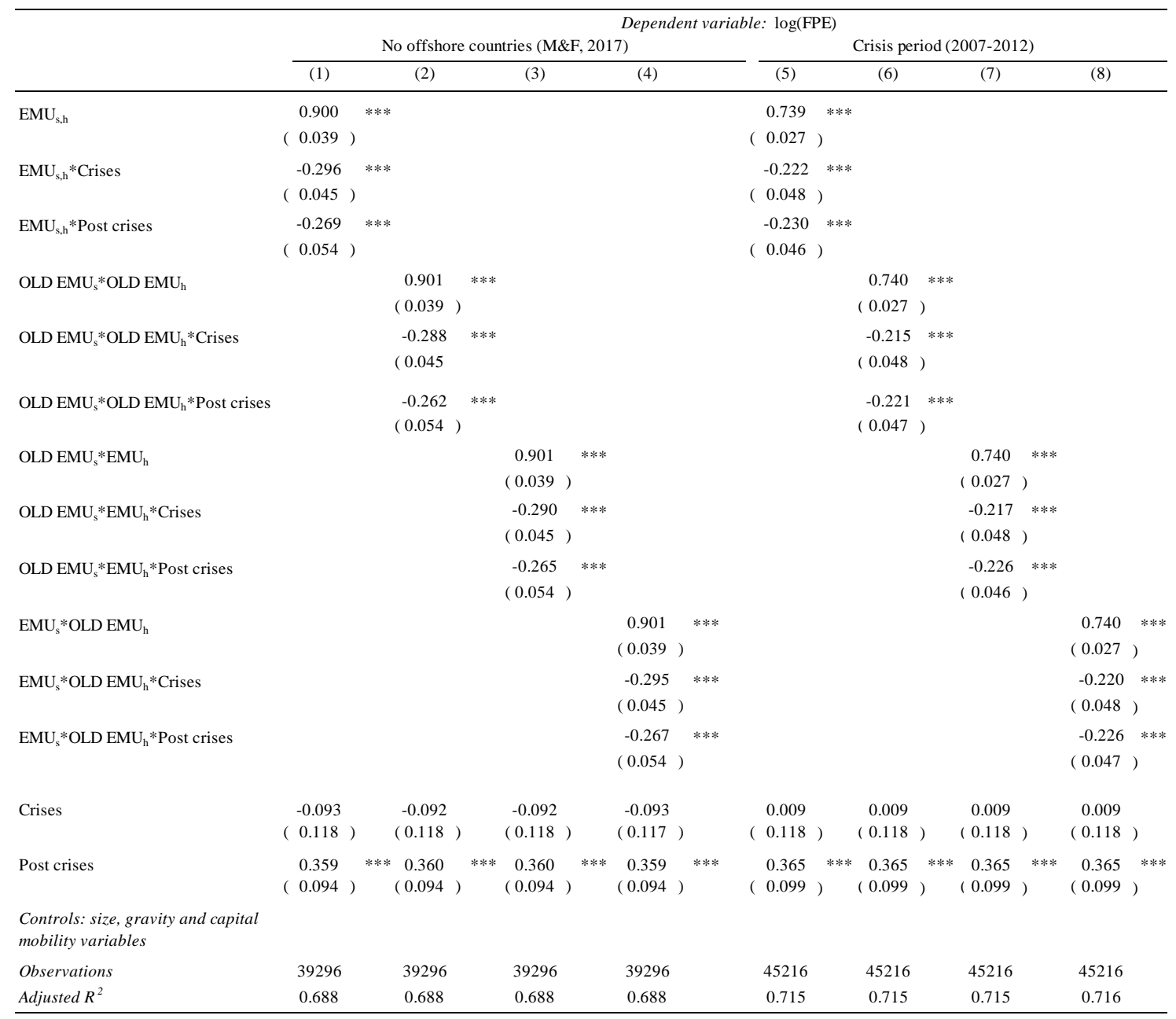

Note. This table reports the results of a Poisson Pseudo Maximum Likelihood regression (Santos Silva and Tenreyro (2006)), as from equation (2) in the main text, with individual country pair fixed-effects and robust Standard errors clustered by year. The dependent variable is $\log \left(F P E_{s h}\right)$, where the subscript $s h$ represents the couple investing country $s$-destination country $h$. All controls of Table 2 are included, but not reported. The columns (1) to (4) replicate the estimates of columns (1) to (4) of Table 4, when the offshore list follows Lane and Milesi-Ferretti (2017). The columns (5) to (8) replicate the estimates of columns (1) to (4), when the crisis period is 2007-2012 (instead of 2008-2012).***,**, and * indicate significance at the 1,5 , and $10 \%$ levels, respectively. 


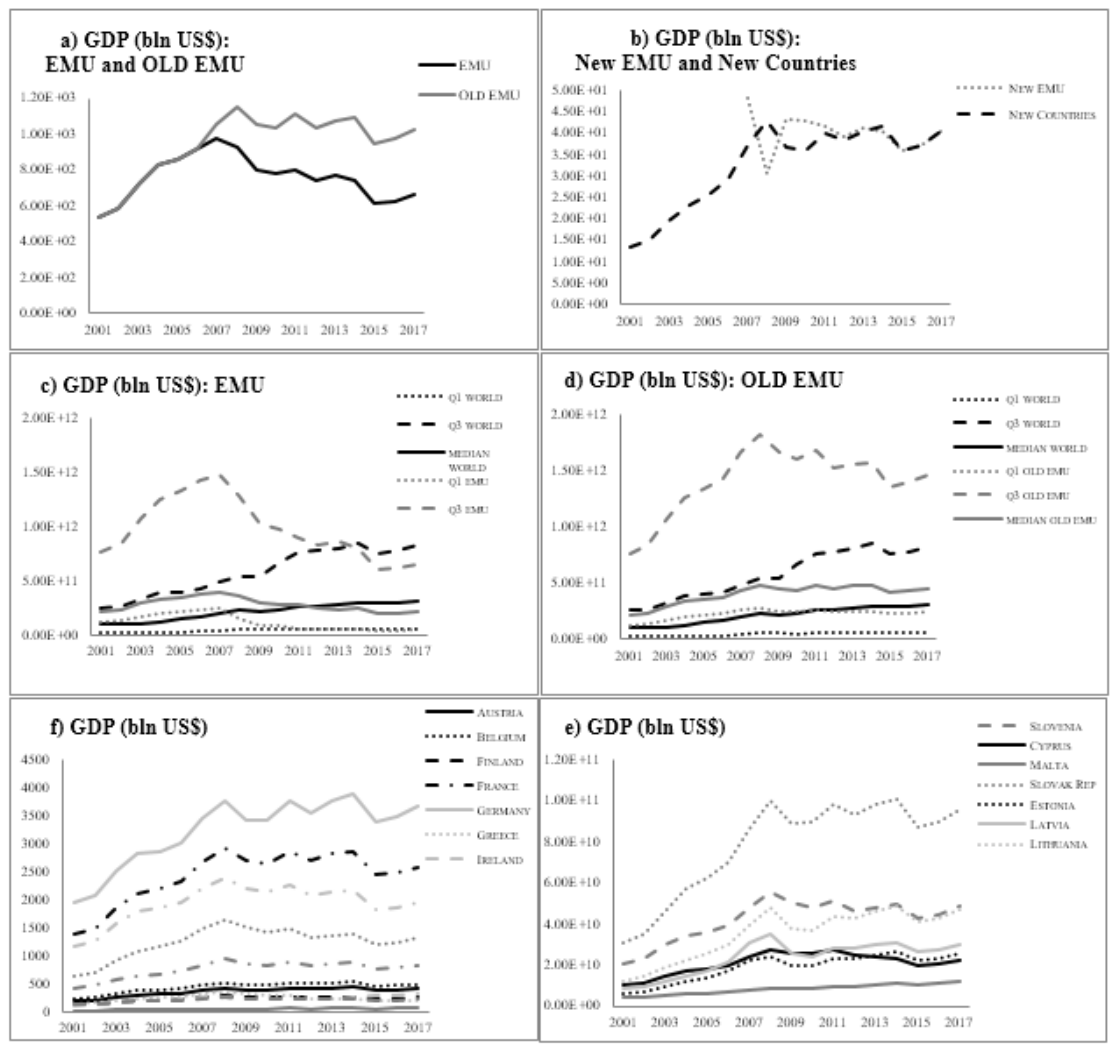

Figure 2A. Dynamics of GDP (bln US\$)

Note. This figure replicates Figure 2 in the main text, replacing the GDP per capita with the GDP. Panel a) refers to EMU and OLD EMU; panel b) to NEW EMU (dummy equal to 1 when the new country enters the union) and New countries (dummy equal to 1 associated to the new countries, regardless of the time of entry); panel c) reports the first quartile (Q1), the median (MEDIAN) and the third quartile (Q3) for EMU countries, together with the respective world average quartiles; panel d) replicates panel c) for OLD EMU countries (right panel); panel e) reports the dynamics for each of the new countries entering the EMU; panel f) reports the dynamics for each of the OLD EMU countries.

Table 10A. FPE and alternative institutional factors

\begin{tabular}{|c|c|c|c|c|}
\hline & \multicolumn{4}{|c|}{ Dependent variable: $\log (\mathrm{FPE})$} \\
\hline & \multicolumn{2}{|c|}{ Govt effect WGI (World Bank) } & \multicolumn{2}{|c|}{ Regulation WGI (World Bank) } \\
\hline & (1a) & (1b) & (2a) & $(2 \mathrm{~b})$ \\
\hline $\mathrm{EMU}_{\mathrm{s}, \mathrm{h}}$ & $\begin{array}{l}0.430 \quad * * * \\
(0.059)^{* *}\end{array}$ & $\begin{array}{l}0.463)^{* * *} \\
(0.091)^{*}\end{array}$ & $\begin{array}{l}0.478 \quad * * * \\
(0.067)^{*}\end{array}$ & $\begin{array}{l}0.482)^{* * *} \\
(0.083)^{*}\end{array}$ \\
\hline H Govt. effect $t_{s}$ & $\begin{array}{c}0.113 \\
(0.089)\end{array}$ & $\begin{array}{l}0.148{ }^{*} \\
(0.082)\end{array}$ & & \\
\hline H Govt. effect ${ }_{h}$ & $\begin{array}{l}0.079 \\
(0.043)\end{array}$ & $\begin{array}{c}0.054 \\
(0.051)\end{array}$ & & \\
\hline $\mathrm{EMU}_{\mathrm{s}, \mathrm{h}} * \mathrm{H}$ Govt. effect ${ }_{\mathrm{s}}$ & $\begin{array}{l}0.148 \quad * \\
(0.076)\end{array}$ & & & \\
\hline $\mathrm{EMU}_{\mathrm{s}, \mathrm{h}} * \mathrm{H}$ Govt. Effect $_{\mathrm{h}}$ & & $\begin{array}{l}0.121 \\
(0.089)\end{array}$ & & \\
\hline H Regulation $_{\mathrm{s}}$ & & & $\begin{array}{l}0.183 \quad * * \\
(0.089)^{*}\end{array}$ & $\begin{array}{l}0.202 \\
(0.079)^{* *}\end{array}$ \\
\hline H Regulation $_{\mathrm{h}}$ & & & $\begin{array}{l}0.109 \quad * \\
(0.060)\end{array}$ & $\begin{array}{l}0.091 \\
(0.070)\end{array}$ \\
\hline $\mathrm{EMU}_{\mathrm{s}, \mathrm{h}} * \mathrm{H}$ Regulation $\mathrm{s}$ & & & $\begin{array}{c}0.093 \\
(0.084)\end{array}$ & \\
\hline $\mathrm{EMU}_{\mathrm{s}, \mathrm{h}} * \mathrm{H}$ Regulation $\mathrm{h}_{\mathrm{h}}$ & & & & $\begin{array}{l}0.096 \\
(0.091)\end{array}$ \\
\hline $\begin{array}{l}\text { Controls: size, gravity an } \\
\text { capital mobility variables }\end{array}$ & & & & \\
\hline Observations & 45216 & 45216 & 45216 & 45216 \\
\hline Adjusted $R^{2}$ & 0.696 & 0.696 & 0.696 & 0.696 \\
\hline
\end{tabular}

Note. This table reports the results of a Poisson Pseudo Maximum Likelihood regression (Santos Silva and Tenreyro (2006)), as from 
equation (2) in the main text, with individual country pair fixed-effect and robust standard errors clustered by year. The dependent variable is $\log \left(F P E_{s h}\right)$, where the subscript $s h$ represents the couple investing country $s$-destination country $h$. All controls of Table 2 are included, but not reported. This table considers the interaction of the bilateral EMU dummy $E M U_{s h}$ with two alternative measures of country governance drawn from the Worldwide Governance Indicators (WGI, World Bank), "Government Effectiveness" and "Regulation". The letter $H$ placed before the institutional variable stands for "High" and indicates a dummy variable equal to 1 if the corresponding institutional variable is above the median, and 0 otherwise. Columns (\#a) consider the size variables relative to the source countries, while columns (\#b) consider the size variables relative to the host countries. ${ }^{* *},{ }^{* *}$, and $*$ indicate significance at the 1,5 , and $10 \%$ levels, respectively.

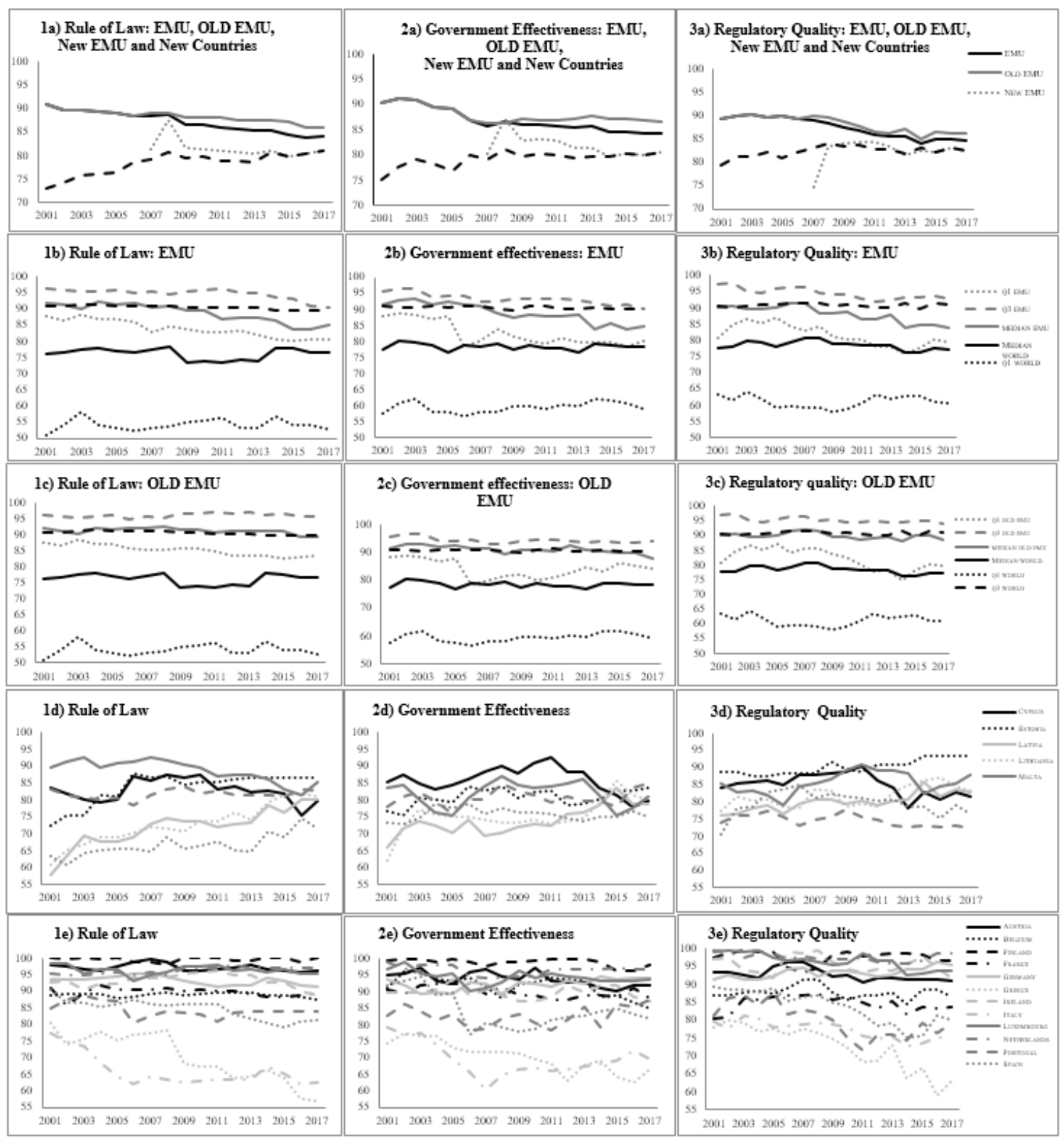

Figure 3A. Dynamics of other institutional factors

Note. This table reports the dynamics of alternative institutional indexes, drawn from the Worldwide Governance Indicators (WGI, World Bank), "Rule of Law" (column 1), "Government Effectiveness" (column 2) and "Regulation" (column 3). Panel a) refers to EMU, OLD EMU, NEW EMU (dummy equal to 1 when the new country enters the union) and New countries (dummy equal to 1 associated to the new countries, regardless of the time of entry); panel b) reports the first quartile (Q1), the median (MEDIAN) and the third quartile (Q3) for EMU countries, together with the respective world average quartiles; panel c) replicates panel b) for OLD EMU countries; panel d) reports the dynamics for each of the new countries entering the EMU; panel e) reports the dynamics for each of the OLD EMU countries. 
Table 12A. NEW EMU and Core/periphery

\begin{tabular}{|c|c|c|c|c|}
\hline & \multicolumn{4}{|c|}{ Dependent variable: $\log (\mathrm{FPE})$} \\
\hline & \multicolumn{2}{|c|}{ NEW EMU and Core } & \multicolumn{2}{|c|}{ NEW EMU and Periphery } \\
\hline & (1) & (2) & (3) & (4) \\
\hline NEW EMU ${ }_{s}^{*}$ Core $_{h}$ & $\begin{array}{l}-0.425 * * * \\
(0.143)\end{array}$ & & & \\
\hline Core $_{\mathrm{s}}{ }^{*} \mathrm{NEW} \mathrm{EMU}_{\mathrm{h}}$ & & $\begin{array}{c}-0.306 * * \\
(0.130)\end{array}$ & & \\
\hline $\mathrm{NEW} \mathrm{EMU}_{\mathrm{s}}{ }^{*}$ Periphery ${ }_{\mathrm{h}}$ & & & $\begin{array}{l}-1.483 * * * \\
(0.281)\end{array}$ & \\
\hline Peripherys $*$ NEW EMU $\mathrm{H}_{\mathrm{h}}$ & & & & $\begin{array}{c}-0.318 \\
(0.220)\end{array}$ \\
\hline Crises & $\begin{array}{c}-0.135 \\
(0.109)\end{array}$ & $\begin{array}{c}-0.135 \\
(0.109)\end{array}$ & $\begin{array}{c}-0.135 \\
(0.109)\end{array}$ & $\begin{array}{c}-0.135 \\
(0.109)\end{array}$ \\
\hline Post crises & $\begin{array}{l}0.265 \text { *** } \\
(0.086)\end{array}$ & $\begin{array}{l}0.265 * * * \\
(0.085)\end{array}$ & $\begin{array}{l}0.265 * * * \\
(0.086)\end{array}$ & $\begin{array}{l}0.265 \text { *** } \\
(0.085)\end{array}$ \\
\hline $\begin{array}{l}\text { Controls: size, gravity al } \\
\text { mobility variables }\end{array}$ & & & & \\
\hline Observations & 45216 & 45216 & 45216 & 45216 \\
\hline Adjusted $R^{2}$ & 0.709 & 0.709 & 0.709 & 0.709 \\
\hline
\end{tabular}

Note. This table reports the results of a Poisson Pseudo Maximum Likelihood regression (Santos Silva and Tenreyro (2006)), as from equation (2) in the main text, with individual country pair fixed-effects and robust

standard errors clustered by year. The dependent variable is $\log \left(F P E_{s h}\right)$, where the subscript sh represents the couple investing country $s$-destination country $h$. All controls of Table 2 are included, but not reported. The columns (1) and (2) consider the investment patterns

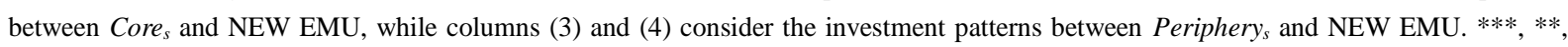
and $*$ indicate significance at the 1,5 , and $10 \%$ levels, respectively.

\section{Copyrights}

Copyright for this article is retained by the author(s), with first publication rights granted to the journal.

This is an open-access article distributed under the terms and conditions of the Creative Commons Attribution license (http://creativecommons.org/licenses/by/4.0/). 